\title{
Giant Neurons in the Rat Reticular Formation: A Sensorimotor Interface in the Elementary Acoustic Startle Circuit?
}

\author{
Kurt Lingenhöhla and Eckhard Friauf \\ Department of Animal Physiology, University of Tübingen, D-72076 Tübingen, Germany
}

The mammalian acoustic startle response (ASR) is a relatively simple motor response that can be elicited by sudden and loud acoustic stimuli. The ASR shows several forms of plasticity, such as habituation, sensitization, and prepulse inhibition, thereby making it an interesting model for studying the underlying neuronal mechanisms. Among the neurons that compose the elementary startle circuit are giant neurons in the caudal pontine reticular nucleus (PnC), which may be good candidates for analyzing the neuronal basis of mammalian behavior. In a first step of this study, we employed retrograde and anterograde tracing techniques to identify the possible sources of input and the efferent targets of these neurons. In a second step, we performed intracellular recordings in vivo, followed by subsequent injections of HRP for morphological identification, thereby investigating whether characteristic features of the ASR are reflected by physiological properties of giant PnC neurons.

Our observations demonstrate convergent, bilateral input from several auditory brainstem nuclei to the $\mathrm{PnC}$, predominantly originating from neurons in the cochlear nuclear complex and the superior olivary complex. Almost no input neurons were found in the nuclei of the lateral lemniscus. As the relatively long neuronal response latencies in several of these auditory nuclei appear to be incompatible with the primary ASR, we conclude that neurons in the cochlear root nuclei most likely provide the auditory input to PnC neurons that is required to elicit the ASR. The giant PnC neurons have a remarkable number of physiological features supporting the hypothesis that they may be a neural correlate of the ASR: (1) they receive short-latency auditory input, (2) they have high firing thresholds and broad frequency tuning, (3) they are sensitive to changes in stimulus rise time and to paired-pulse stimulation, (4) repetitive acoustic stimulation results in habituation of their response, and (5) amygdaloid activity enhances their response to acoustic stimuli. Anterograde tracing showed that most giant $\mathrm{PnC}$ neurons are reticulospinal cells. Axon collaterals and terminal arbors were found in the reticular formation as well as in cranial and spinal motoneuron pools.

The results of this study indicate that giant PnC neurons

\footnotetext{
Received Mar. 25, 1993; revised Aug. 4, 1993; accepted Aug. 12, 1993

This study was supported by DFG Grants SFB 307 and Fr 772/1-2 and by a scholarship from Graduiertenkolleg Neurobiologie of the University of Tühingen to K.L. We thank Dr. Horst Herbert for technical advise, Dr. Michael Koch for critically reading the manuscript, and Gwynn Goldring for correcting our English.

Send correspondence to Eckhard Friauf at the above address.

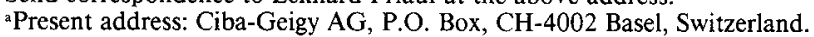
Copyright (C) 1994 Society for Neuroscience $0270-6474 / 94 / 141176-19 \$ 05.00 / 0$
}

form a sensorimotor interface between the cochlear nuclear complex and cranial and spinal motoneurons. This neuronal pathway implies that the elementary acoustic startle circuit is composed of only three central relay stations and thus appears to be organized more simply than assumed in the past.

[Key words: acoustically elicited behavior, auditory brainstem, sensorimotor interface, pontine reticular formation, cochlear root neurons, spinal cord, reticulospinal neurons, intracellular recording, intracellular labeling, anterograde and retrograde tracing]

To understand the neuronal mechanisms of behavior, neurobiologists need neural circuits that are simple enough to delineate. Very successful attempts toward this goal particularly have been made in invertebrates [e.g., gill withdrawal reflex (Kandel, 1991) and negative phototaxis in marine snails (Crow, 1988)] and in lower vertebrates (e.g., Mauthner escape system and swimming behavior in teleost fish; Roberts, 1990; Eaton et al., 1991; Grillner et al., 1991), yet were seldom performed in higher vertebrates. The mammalian startle response is a relatively simple motor response to various external stimuli that occurs in a wide variety of species, including humans (Landis and Hunt, 1939). One form of the startle response, the acoustic startle response (ASR), can be elicited by sudden and loud acoustic stimuli (Prosser and Hunter, 1936). The ASR consists of a sequence of reflexive muscle contractions, involving muscles of the head, neck, forelimbs, and hindlimbs (summarized in Caeser et al., 1989). In the rat, very short electromyographic latencies of only 5-6 msec occur in head and neck muscles (Hammond et al., 1972; Cassella et al., 1986; Pilz et al., 1988; Rosen and Davis, 1988; Caeser et al., 1989; Pellet, 1990), with forelimb muscles contracting after $6-7 \mathrm{msec}$ (Ison et al., 1973), and hindlimb muscles after 8-10 msec (Ison et al., 1973; Davis et al., 1982a). These very short latencies indicate that the elementary neuronal circuit mediating the ASR involves only a few central synapses and may thus be relatively simply organized, suggesting that there is a good chance of identifying the participating neuronal elements, and then using the ASR as a model for investigating the neuronal basis of behavior in mammals.

Prosser and Hunter (1936) were the first to propose a complete elementary startle circuit, yet the most influential report was. later published by Davis et al. (1982a), based mainly on electrical stimulation and lesion studies. Davis and colleagues postulated an elementary startle circuit that comprises five central relay stations as well as the neuromuscular junction: auditory nerve, ventral cochlear nucleus (VCN), nuclei of the lateral lemniscus (NLL), nucleus reticularis pontis caudalis, spinal inter- 
neurons, motoneurons, and muscles. There is no doubt that obligatory parts of the elementary acoustic startle circuit are neurons in the cochlear nuclear complex as well as cranial and spinal motoneurons. However, the linking neuronal elements, which form the sensorimotor interface, need to be further elucidated. We believe that the understanding of the circuitry would benefit from an analysis using modern and sensitive methods. These may help clarify apparent contradictions in the existing data. For example, whereas Davis et al. (1982a) thought that the NLL contributes to the ASR, Shammah-Lagnado et al. (1987) failed to find labeled NLL neurons after injections of HRP into the rat pontine reticular formation. Furthermore, the earliest auditory responses in the rat NLL are found after $4.4 \mathrm{msec}$ (Preuß, 1991), a latency that appears to be too long to account for the short ASR latencies of 5-6 msec seen in head muscles (Hammond et al., 1972; Cassella et al., 1986; Pilz et al., 1988; Rosen and Davis, 1988; Caeser et al., 1989; Pellet, 1990), making it rather unlikely that NLL neurons participate in the primary ASR. Furthermore, Davis and colleagues originally postulated that the dorsal NLL is a relay station (Davis et al., 1982a; Davis, 1984), yet later proposed the ventral NLL as a more likely candidate (e.g., Davis et al., 1986), and most recently claimed that "an area just medial and ventral to the ventral nucleus of the lateral lemniscus" is involved (Davis, 1992).

Over the past years, compelling evidence has been provided pointing to the involvement of the pontine reticular nucleus (which is equivalent to the nucleus reticularis pontis caudalis) in the ASR (Szabó and Hazafi, 1965; Hammond, 1973; Leitner et al., 1980; Davis et al., 1982a; Boulis and Davis, 1989; Müller and Klingberg, 1989; Yeomans et al., 1989; Koch et al., 1992). Neurons in this area can be driven acoustically (Siegel and McGinty, 1977; Siegel and Tomaszewski, 1983; Lingenhöhl and Friauf, 1992) and neuronal activity correlates nicely with electromyograms when startle-eliciting stimuli are presented $(\mathrm{Wu}$ et al., 1988), providing further evidence that this reticular region participates in the ASR. However, the pontine reticular nucleus contains heterogeneous cell populations with small, medium, and very large neurons (Taber, 1961; Valverde, 1961; Andrezik and Beitz, 1985; Newman, 1985). Therefore, it is difficult to attribute extracellular recordings to a certain cell population. In a recent study, we tried to circumvent this problem by using intracellular recording techniques combined with intracellular injection of HRP in the rat (Lingenhöhl and Friauf, 1992). We identified and characterized giant neurons in the caudal pontine reticular nucleus $(\mathrm{PnC})$ that receive acoustic input with a mean EPSP onset latency of $2.6 \mathrm{msec}$ and a mean spike latency of 5.2 msec. These latencies are short enough to make these cells a good candidate for mediating the ASR. This conclusion is consistent with findings by Koch et al. (1992), who used a neuronspecific, axon-sparing lesion technique and demonstrated a close correlation between the number of giant $\mathrm{PnC}$ neurons and the amplitude of the ASR.

The present study was designed to identify the afferent input onto these neurons, to reveal their efferent projections, and to find response properties of giant $\mathrm{PnC}$ neurons that correlated with some of the characteristics of the ASR, for example, sensitivity to changes in rise time (Fleshler, 1965; Pilz, 1989), shortterm habituation (Prosser and Hunter, 1936; Moyer, 1963; Davis and File, 1984), prepulse inhibition (Hoffman and Searle, 1965; Ison and Hammond, 1971; Hoffman and Ison, 1980; Hoffman et al., 1980; Ison and Hoffman, 1983), and fear conditioning (Brown et al., 1951; Hitchcock and Davis, 1986; Davis et al., 1991; Davis, 1992). To achieve our goal, we used retrograde and anterograde tracing techniques as well as intracellular electrophysiology with subsequent HRP injections. Our data show that giant PnC neurons fulfill all of the above-tested criteria and that these neurons can therefore be considered a sensorimotor interface in the elementary startle circuit. Our results further suggest that the elementary startle circuit is composed of fewer synapses than previously thought.

A preliminary report of this study has been published (Lingenhöhl et al., 1991).

\section{Materials and Methods}

Forty-nine adult female Sprague-Dawley rats $(2 \mathrm{l} 0-390 \mathrm{gm})$ were used in the present study. Forty animals were used for intracellular electrophysiology and nine animals for anterograde or retrograde tracing experiments.

\section{Intracellular electrophysiology and HRP injections}

A total of 40 animals were used for intracellular electrophysiology and HRP injections. A full description of the experimental setup, the surgical, electrophysiological, and histological procedures, as well as the data analysis has been provided elsewhere (Lingenhöhl and Friauf, 1992).

\section{Acoustic stimulation}

Pure-tone (range, 5-55 kHz), linearly frequency-modulated $(1-50 \mathrm{kHz})$, or broad-band noise pulses (range, $5-100 \mathrm{kHz}$ ) were presented in a dichotic stimulation system coupled to the two hollow ear bars. Pulses were presented at $1.5 \mathrm{~Hz}(0.5 \mathrm{~Hz}$ in paired-pulse experiments) and usually had a duration of $80 \mathrm{msec}$ (range, $20-250 \mathrm{msec}$ ) and transition times of $2.5 \mathrm{msec}$ (range, $2.5-40 \mathrm{msec}$ ). The acoustic system was calibrated in four animals as described previously (Friauf and Ostwald, 1988), and maximal stimulus intensities reached $80 \mathrm{~dB}$ SPL. Prepulses, when applied, consisted of noise pulses, 20-80 msec in duration, presented with their onset $40-500$ msec prior to the onset of the sccond stimulus (interstimulus interval).

\section{Electrical stimulation}

A total of 16 animals were prepared for electrical stimulation of brain nuclei or of the spinal cord. Stimulating electrodes were twisted copper wires (total diameter, $200 \mu \mathrm{m}$ ) that were insulated except for their tips. These electrodes were stereotaxically implanted into the amygdaloid complex (five animals), the superior colliculus (two animals), and the ventral white matter of the thoracic spinal cord ( 16 animals). In addition, electrodes were placed on the surface of the dorsal cochlear nucleus (DCN; five animals) under visual guidance. Stimuli were constant-current pulses of $70 \mu \mathrm{sec}$ duration with amplitudes between 0.1 and 10 $\mathrm{mA}$.

\section{Data analysis}

Morphological reconstruction. Labeled neurons were drawn in the coronal or sagittal plane with the aid of a camera lucida at a magnification of $300-400 \times$. By means of a computerized system, the dendritic organization and axonal course were reconstructed three-dimensionally. A detailed description of the procedure has been given previously (Friauf, 1986; Sommer et al., 1993). Morphometric measurements were performed at a magnification of $500 \times$. Axonal diameters were measured at three locations along the axon: close to the cell body, before bending into the medial longitudinal fascicle, and within the medullary reticular formation. At each location, three measurements were made and then averaged.

Physiology. Thorough analysis of the electrophysiological data was performed off line. EPSP latencies and spike latencies were measured between the onset of the acoustic/electrical stimulus and the onset of the EPSP and spike, respectively. Each given latency for a single cell is the arithmetic mean of 20 records. The mean values of all cells were calculated as the arithmetic mean of the individual mean values. The maximal EPSP amplitude was measured by averaging the signals from 20 records. The tonic EPSP amplitude was measured three times, 25 $\mathrm{msec}$ and $50 \mathrm{msec}$ after reaching the maximal amplitude and just before the falling phase of the acoustic stimulus, and is given as the arithmetic mean of these values. Spike thresholds were determined audiovisually. 
EPSP thresholds and spike thresholds were determined at a neuron's best frequency. Following electrical stimulation of the spinal cord, spikes were classified as antidromic when they appeared with short and constant latency.

\section{Methodological considerations}

All of our electrophysiological experiments were performed in deeply anesthetized animals that did not show an ASR. Therefore, we were unable to correlate neuronal responses with behavioral activity (e.g., EMG responses), and consequently, the discussion of our data is limited to a comparison of parallels that are manifested in both neuronal and behavioral responses. Furthermore, since we could not produce acoustic stimuli above $80 \mathrm{~dB}$ SPI, with our closed acoustic system, we were unable to mimic exactly the stimulus conditions used in behavioral ASR tests. Thus, our results do not prove any causality between the activity of giant PnC neurons and the ASR.

\section{Tracing experiments}

Nine animals were anesthetized with intramuscular injections of a mixture of ketamine $(100 \mathrm{mg} / \mathrm{kg})$ and xylazine $(2 \mathrm{mg} / \mathrm{kg})$ and placed in a stereotaxic frame. The initial surgical procedure was the same as described above, except that the cerebellum was left intact. The local anesthetic xylocaine was administered before craniotomy. Following the tracer injection (Fluoro-Gold or Phaseolus vulgaris leucoagglutinin), the wound was sutured and covered with Nebacetin.

Retrograde tracing with Fluoro-Gold. The retrograde fluorescent tracer Fluoro-Gold (Fluorochrome Inc.) was injected into the PnC of five rats to identify the afferent input to the PnC. Injection pipettes with tip diameters of $40-60 \mu \mathrm{m}$ were inserted into the brains at a lateral angle of $10^{\circ}$ and a rostral angle of $20^{\circ}$. A $2 \%$ solution of Fluoro-Gold in 0.1 $\mathrm{M}$ cacodylate buffer at pH 7.5 was iontophoretically injected $(+6 \mu \mathrm{A}$, 10-15 min, $5 \mathrm{sec}$ on/off). After a survival time of $5 \mathrm{~d}$, the rats were deeply anesthetized and perfused through the heart with $0.9 \%$ saline followed by $500 \mathrm{ml}$ of ice-cold $4 \%$ paraformaldehyde in $0.1 \mathrm{M}$ phosphate buffer at $\mathrm{pH}$ 7.4. The brains were removed, postfixed overnight in a $30 \%$ sucrose fixative, cut with a freezing microtome in the coronal plane at $40 \mu \mathrm{m}$, and divided into two series. One series was mounted directly onto gelatin-coated slides, air dried, and enclosed with DePeX and coverslips. The second series was stained with thionin. Sections from the lower medulla to the rostral part of the superior colliculus were viewed with fluorescent illumination, employing a UV filter set for Fluoro-Gold. The distribution of retrogradely labeled neurons was mapped with the aid of an $\mathrm{x}, \mathrm{y}$-plotter coupled to the microscope stage. Cytoarchitectural boundaries were defined by superimposing the adjacent thionin-staincd scctions with the plots.

Anterograde tracing with Phaseolus vulgaris leucoagglutinin. The anterograde tracer Phaseolus vulgaris leucoagglutinin (PHA-L; Vector) was injected into the PnC of four rats in order to identify the efferent projection pattern of PnC neurons. Injection pipettes were inserted into the brains at a lateral angle of $10^{\circ}$ and a rostral angle of $20^{\circ}$. Injections were made with glass micropipettes (tip diameter, $40 \mu \mathrm{m}$ ) from which $2.5 \%$ PHA-L in $10 \mathrm{~mm}$ phosphate buffer at $\mathrm{pH} 8.0$ was iontophoresed, using pulsed positive current pulses ( $+5 \mu \mathrm{A}, 5 \mathrm{sec}$ on/off, $15-20 \mathrm{~min}$ ). After $14 \mathrm{~d}$, the animals were deeply anesthetized and perfused through the heart with $0.1 \mathrm{M}$ PBS, followed by two fixatives according to the twostep pH-change protocol of Berod et al. (1981). Briefly, the rats were perfused with $180 \mathrm{ml}$ of ice-cold $4 \%$ paraformaldehyde in $0.1 \mathrm{M}$ sodium acetate buffer at $\mathrm{pH} 6.5$, followed by $300 \mathrm{ml}$ of ice-cold $4 \%$ paraformaldehyde in $0.1 \mathrm{~m}$ borate buffer at $\mathrm{pH} \mathrm{11.0.} \mathrm{Brains} \mathrm{and} \mathrm{spinal} \mathrm{cords}$ were removed and postfixed overnight at $4^{\circ} \mathrm{C}$ in the borate buffer fixative containing $30 \%$ sucrose. Coronal brain sections were cut on a freezing microtome at $40 \mu \mathrm{m}$, starting at the level of the lower medulla and ending at the level of the superior colliculus. Sections were divided into four series; one series was directly thionin stained, another was used for immunocytochemistry, and two series were discarded. The spinal cord was cut into three segments that corresponded roughly to the cervical, thoracic, and lumbar spinal cord. In one animal, the spinal cord was cut horizontally. The spinal cords of the remaining three animals were cut in the sagittal plane on a freezing microtome at $60 \mu \mathrm{m}$ and divided into two series. One series was directly Nissl stained and the other was used for immunocytochemistry.

Immunocytochemistry. Sections were immunocytochemically processed by the peroxidase-antiperoxidase (PAP) method (Sternberger, 1979) to identify PHA-L-labeled fibers. This procedure has been pre- viously described in detail (Kandler and Herbert, 1991). Briefly, nonspecific immune blocking with normal swine serum for $1 \mathrm{hr}$ was followed by $36 \mathrm{hr}$ of incubation (at $4^{\circ} \mathrm{C}$ ) with primary antibody (rabbit anti-PHAL) diluted 1:3000 and containing 1\% normal swine serum and $1 \%$ bovine serum albumin. The sections underwent reaction with unlabeled swine anti-rabbit $\operatorname{IgG}$ antiserum and were then incubated in the rabbit-PAP complex. The final visualization of the PHA-I was achieved with $0.02 \%$ 3,3 -diamidinobenzidine and $0.01 \% \mathrm{H}_{2} \mathrm{O}_{2}$. Thorough washing in Trisbuffered saline was always performed between steps. Sections were mounted, dehydrated, cleared in xylene, and coverslipped. Microscopic analysis was performed under bright-field illumination and the distribution of PHA-L-labeled fibers in the spinal cord was mapped with a camera lucida in two animals.

\section{Results}

Afferent projections from auditory brainstem nuclei into the $P n C$

Following Fluoro-Gold injections into the PnC (Fig. 1A,B), retrogradely labeled neurons were seen bilaterally in several auditory brainstem nuclei. Within the cochlear nuclear complex, intensely labeled cell bodies were observed in the cochlear root nucleus (CRN; Fig. 1C), in deep layers of the DCN (Fig. 1D), and in the VCN (Fig. 1C). In the superior olivary complex (SOC), cell bodies were mainly labeled in the lateral superior olive (LSO; Fig. $1 E$ ). Some labeled neurons were also seen in the lateral nucleus of the trapezoid body (LNTB), and only few labeled neurons were present in other areas of the SOC. Only a negligibly small number of cells could be retrogradely labeled in the NLL. Other brainstem nuclei that are involved in the ascending auditory pathway, such as the central nucleus of the inferior colliculus and the ventral part of the medial geniculate body, were free of labeling. However, labeled neurons were found in the external cortex of the inferior colliculus, which is considered part of the descending auditory pathway (Huffman and Henson, 1990; Caicedo and Herbert, 1993). In the DCN and the LSO, labeled neurons were distributed throughout the nuclear domains (Fig. 2). Since these nuclei are tonotopically organized, it appears that there is no frequency-sclective projection from these nuclei into the $\mathrm{PnC}$, but rather a convergence of input from the entire hearing range of the rat.

The majority of auditory brainstem neurons that projected into the PnC were located contralaterally (Table $1 ; 65 \%$ contralateral, $35 \%$ ipsilateral). Fifty-one percent of the auditory input neurons were counted in the cochlear nuclear complex (37\% contralateral, $14 \%$ ipsilateral) and $49 \%$ in the SOC. In terms of cell number, the most prominent auditory input to the PnC derived from the DCN, which accounted for $39 \%(28 \%$ contralateral, $11 \%$ ipsilateral). Neurons in the VCN contributed $9 \%$, and CRN neurons, $1 \%$ of the auditory input. Within the SOC, LSO neurons were clearly the most frequently labeled cells ( $27 \%$ of the total number), followed by the LNTB neurons (6\%). As in the DCN, the majority of labeled LSO neurons were found contralaterally ( $20 \%$ vs $7 \%$ ipsilateral).

From our tracing experiments it remained unclear whether the labeled neurons in auditory brainstem nuclei indeed contact giant $\mathrm{PnC}$ neurons and whether their input is excitatory. In order to elucidate further these open questions, we stimulated the DCN electrically while recording intracellularly from giant PnC neurons. Seven of nine cells tested responded with EPSPs that could give rise to action potentials (Fig. 3); the remaining two cells could not be synaptically driven with the maximal stimulus intensity used. The latencies between the electrical stimulus and the EPSP onset ranged between 1.4 and $3.8 \mathrm{msec}$ (mean, 2.2 msec), making a monosynaptic connection between the DCN 

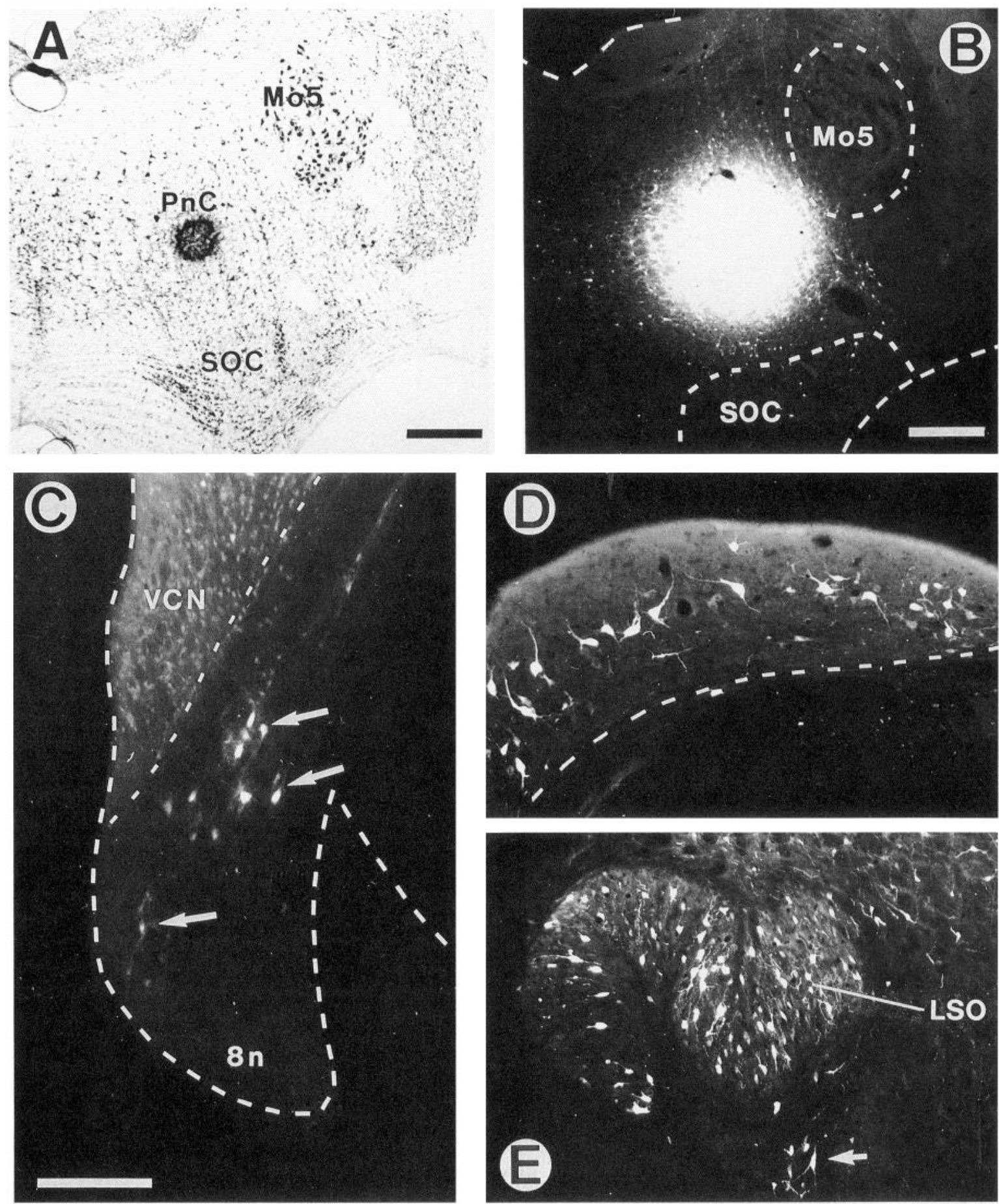

Figure 1. Afferent projections from pontine auditory nuclei into the PnC. $A$, Thionin-stained section showing the center of the injection site (gliosis) following application of Fluoro-Gold into the PnC. $B$, Same section as in $A$, but under epifluorescent illumination, showing fluorescent halo restricted to the PnC. $C-E$, Retrogradely labeled cell bodies contralateral to the injection site. $C$, CRN (arrows) and VCN. Note autofluorescent background and few labeled somata in VCN. $D$, DCN. $E$, LSO and LNTB (arrow). $8 n$, auditory nerve. Scale bars: $A$ and $B, 500 \mu$ m; $C-E$, $250 \mu \mathrm{m}$.

and $\mathrm{PnC}$ giant neurons likely. At stimulus intensities well above firing threshold a short-latency action potential, which was followed by a burst of action potentials, was observed (Fig. 3).

\section{Short-latency excitatory auditory input to giant PnC neurons}

The response characteristics of $73 \mathrm{PnC}$ neurons were studied intracellularly in response to broad-band noise or pure-tone pulses, which were presented via two hollow ear bars. Thirty- one neurons were intracellularly labeled with HRP to enable unambiguous identification of the neuronal type and subsequent morphological analysis (Fig. $4 B$ ). As we have previously presented the general response characteristics and the somatodendritic details of giant $\mathrm{PnC}$ neurons in great detail (Lingenhöhl and Friauf, 1992), we will focus here on physiological data that may substantiate the role of these cells in the ASR.

Giant PnC neurons were excited at short latencies by acoustic 


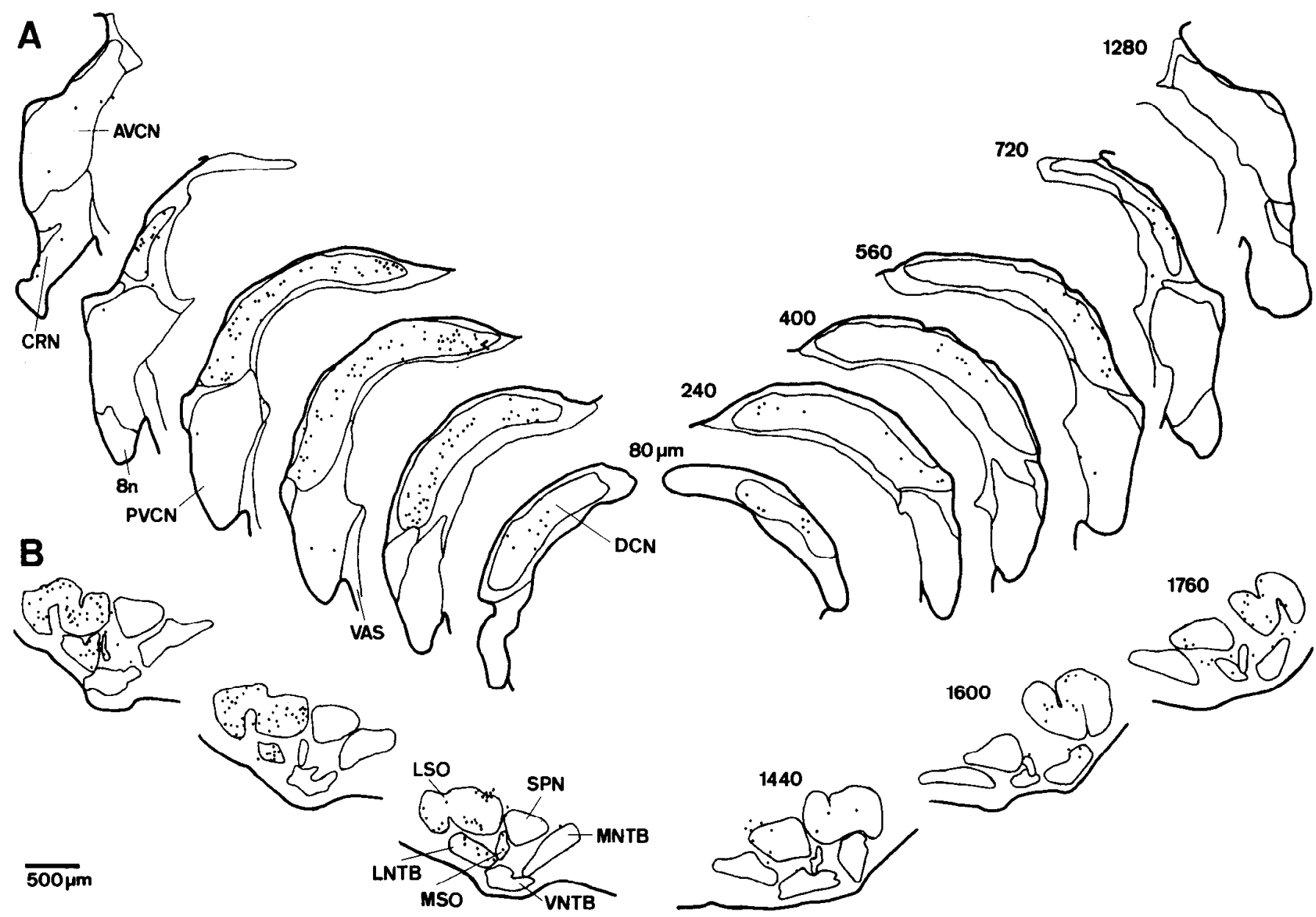

Figure 2. Distribution of Fluoro-Gold-labeled auditory neurons that project into the PnC: coronal sections showing the cochlear nuclear complex $(A)$ and the SOC $(B)$. Each dot represents one cell body. The injection was placed into the right PnC; nuclei on the left side of the brainstem are shown on the left, and those on the right side are shown on the right. Numbers depict the distance of the corresponding section from the caudalmost section through the DCN. $M N T B$, medial nucleus of the trapezoid body; VAS, ventral acoustic stria. For other abbreviations, see Table 1 notes.

stimuli (Fig. 4A). Following noise pulses presented at $80 \mathrm{~dB}$ SPL, the mean latency from the stimulus onset to the EPSP onset was $2.6 \mathrm{msec} \pm 0.82 \mathrm{msec} \mathrm{SD}$, and to the spike onset, $5.2 \mathrm{msec} \pm 1.83 \mathrm{msec} \mathrm{SD}$. As will be extensively discussed later on, both of these latencies are in perfect register with the latency of the ASR.

To summarize so far, giant PnC neurons fulfill several obligatory criteria to participate in the elementary startle circuit: they receive direct input from auditory nuclei in the pontine brainstem and this input is excitatory and of short latency.

\section{High firing thresholds and broad frequency tuning}

By means of our intracellular recordings, we were able to determine spike thresholds as well as EPSP thresholds. Using noise pulses, the F.PSP thresholds ranged from $30 \mathrm{~dB}$ SPI to $80 \mathrm{~dB}$ SPL, but only 1 of 36 neurons had a threshold as low as $30 \mathrm{~dB}$

Table 1. Quantitative distribution of auditory brainstem neurons that project into the PnC

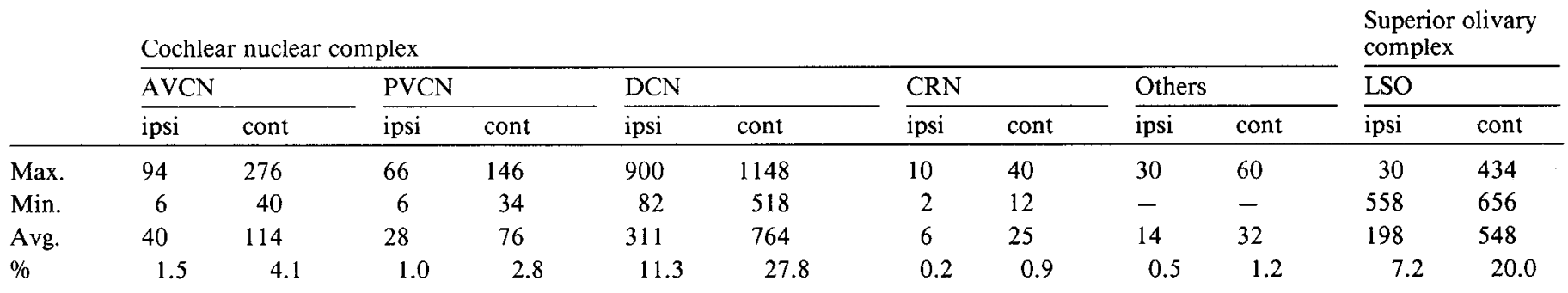

Fluoro-Gold was injected into the PnC of five animals and retrogradely labeled neurons were counted bilaterally in the cochlear nuclear complex and the superior olivary complex. The average total number of labeled neurons was $2745(-100 \%)$. Max., Min., and Avg. refer to maximum, minimum and average number of labeled neurons, respectively. "Others" refers to areas outside the nuclei proper, for example, to the acoustic stria, the granular cell layer, or periolivary regions. AVCN, 


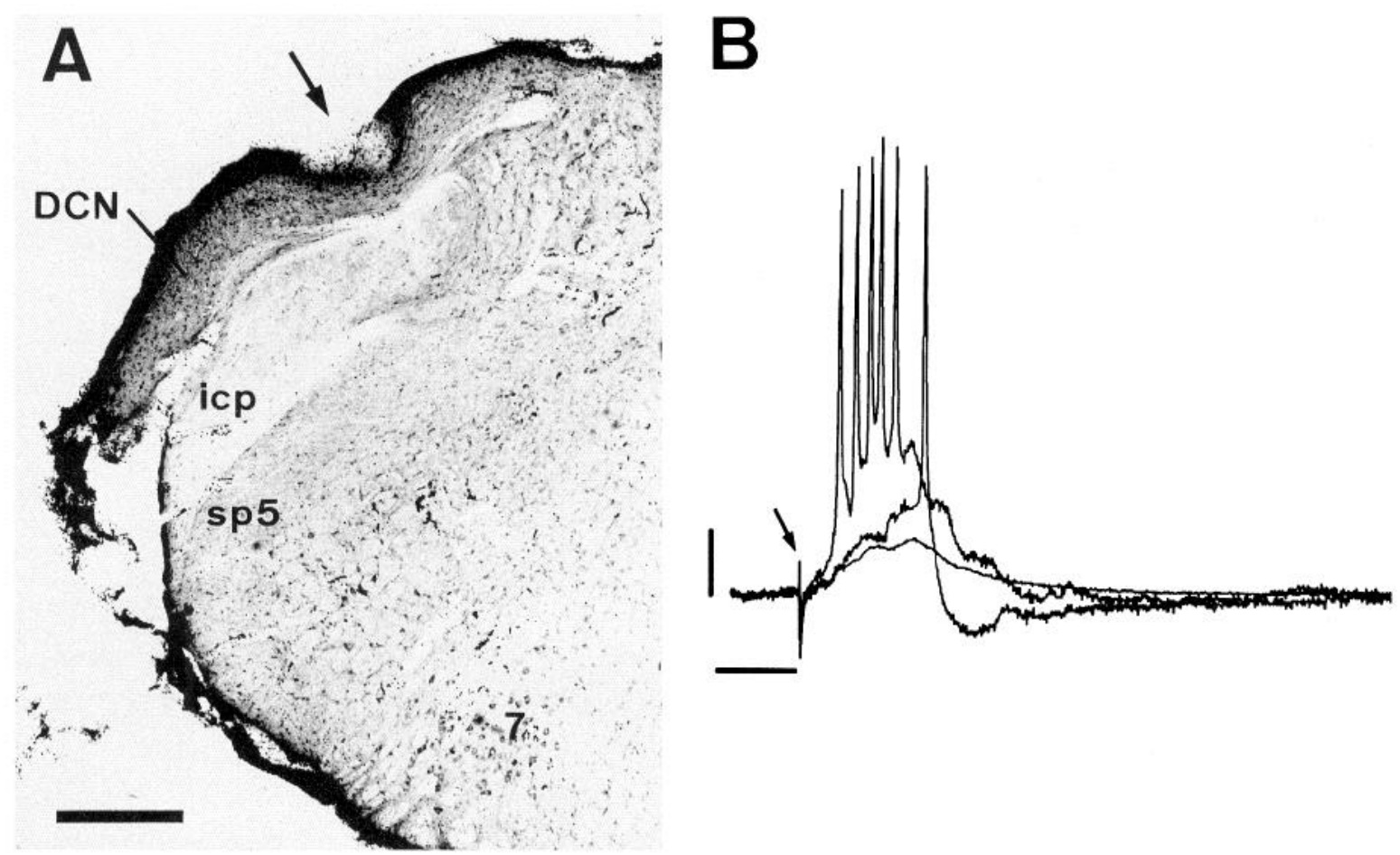

Figure 3. Short-latency, excitatory synaptic input from the DCN to giant PnC neurons. $A$, Coronal section through the DCN showing the site of electrical stimulation (arrow). Scale bar, $500 \mu \mathrm{m}$. B. Intracellular responses of a giant PnC neuron following electrical stimulation of the DCN. Three excitatory responses at increasing stimulus intensities are superimposed. Low stimulus intensities result in subthreshold EPSPs (see averaged trace with little noise, based on 20 stimulus presentations); moderate stimulus intensities result in EPSPs that give rise to a single action potential, and high stimulus intensities elicit a burst of action potentials. Arrow points to the stimulus artifact. icp, inferior cerebral peduncle; $s p 5$, spinal trigeminal tract; 7, facial nucleus. Resting potential, $-69 \mathrm{mV}$. Calibration: $10 \mathrm{msec}, 5 \mathrm{mV}$.

SPL, whereas 17 had EPSP thresholds above $60 \mathrm{~dB}$ SPL (Fig. $5 A$ ). These results indicate that giant $\mathrm{PnC}$ neurons have high thresholds to acoustic stimuli, which is further corroborated by the finding that $50 \%$ of the neurons tested had spike thresholds above 80 dB SPL (Fig. $5 B$ ). The high thresholds found in giant PnC neurons imply that these cells respond only to loud acoustic stimuli and generate action potentials at sound intensities that are similar to those that elicit an ASR.

Following frequency-modulated stimuli, EPSPs and action potentials were elicited over a frequency range between 10 and $40 \mathrm{kHz}$, indicating that $\mathrm{PnC}$ neurons are not very frequency selective but instead broadly tuned. As the ASR can be elicited by tonal stimuli throughout the rat's hearing range, our data are in good register with the behavior. They are also consistent with the above-mentioned observation of convergent input from auditory brainstem nuclei along the entire frequency axis.

\section{Sensitivity to stimulus rise time}

Acoustic stimuli with short rise times are required to elicit an ASR, whereas stimuli with long rise times are less effective or even ineffective (Fleshler, 1965; Pilz, 1989). In order to investigate whether an equivalent phenomenon occurs in giant $\mathrm{PnC}$ neurons, we tested the effect of the stimulus rise time on the response characteristics of five neurons. When stimuli with a relatively short rise time of $2.5 \mathrm{msec}$ were applied, giant $\mathrm{PnC}$ neurons typically showed EPSPs with a pronounced on component, followed by a tonic component of lower amplitude (Fig. $6 \mathrm{~A}$ ). In contrast, stimuli with longer rise times such as $20 \mathrm{msec}$

Table 1. Continued

\begin{tabular}{|c|c|c|c|c|c|c|c|c|c|c|c|c|}
\hline & \multicolumn{12}{|c|}{ Superior olivary complex } \\
\hline & \multicolumn{2}{|c|}{ MSO } & \multicolumn{2}{|l|}{ SPN } & \multicolumn{2}{|c|}{ LNTB } & \multicolumn{2}{|c|}{ VNTB } & \multicolumn{2}{|l|}{ RPO } & \multicolumn{2}{|c|}{ Others } \\
\hline & ipsi & cont & ipsi & cont & ipsi & cont & ipsi & cont & ipsi & cont & ipsi & cont \\
\hline Max. & 10 & 18 & 188 & 10 & 300 & 170 & 110 & 34 & 158 & 108 & 136 & 86 \\
\hline Min. & - & 4 & 20 & - & - & 22 & - & - & 32 & 4 & 38 & 36 \\
\hline Avg. & 4 & 10 & 65 & 4 & 70 & 99 & 57 & 14 & 79 & 50 & 81 & 56 \\
\hline$\%$ & 0.1 & 0.4 & 2.4 & 0.1 & 2.5 & 3.6 & 2.1 & 0.5 & 2.9 & 1.8 & 3.0 & 2.0 \\
\hline
\end{tabular}

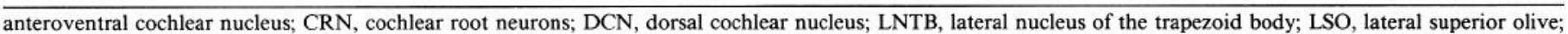

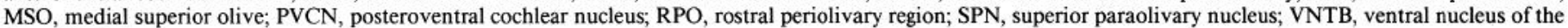
trapezoid body. 

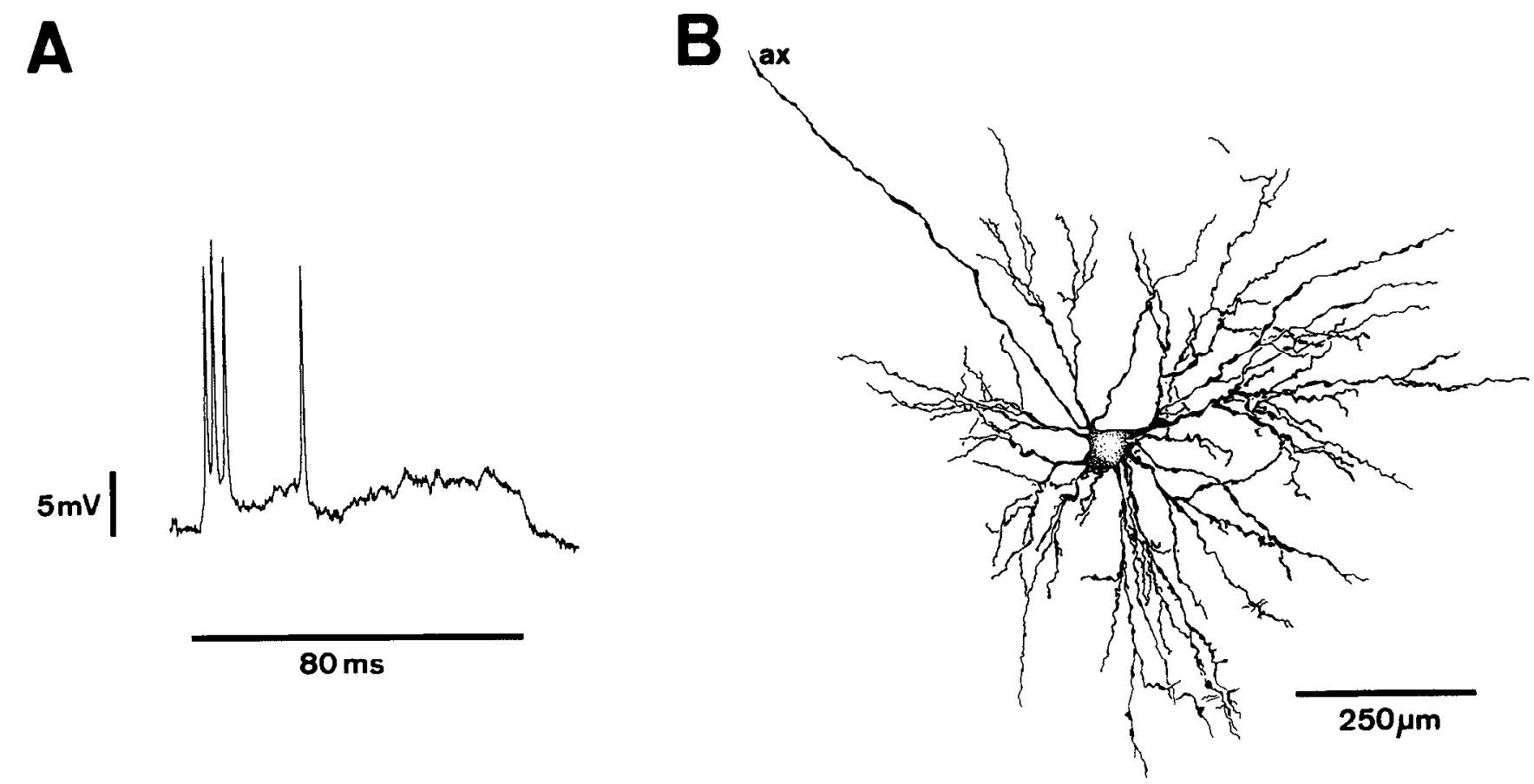

Figure 4. Example of the auditory response and the somatodendritic morphology of giant PnC neurons. $A$, EPSP giving rise to action potentials following stimulation with a pure tone pulse. Resting potential, $-51 \mathrm{mV}$. B. Camera lucida drawing an HRP-labeled giant PnC neuron. ax, axon.

elicited EPSPs in which the amplitude of the on component was significantly reduced, whereas the amplitude of the tonic component was often increased (Fig. 6A). Gradual increases of the stimulus rise time resulted in prolonged EPSP onset latencies (Fig. $6 B$ ) and a slower slope of the EPSP onset (Fig. $6 C$ ). In one neuron the EPSP latency decreased from $5.3 \mathrm{msec}$ to $3.2 \mathrm{msec}$ when the stimulus rise time was reduced from $20 \mathrm{msec}$ to 2.5 mscc. The spikc response was also affected by changes in the stimulus rise time and the latency of one neuron decreased from $20.8 \mathrm{msec}$ to $6.2 \mathrm{msec}$ when the stimulus rise time was reduced from $40 \mathrm{msec}$ to $2.5 \mathrm{msec}$. A clear on component in the peristimulus time histogram (PSTH; composed of one or two spikes) was only present when stimuli with short rise times were offered (Fig. 6D1-D3,E1-E3). The observed relation between EPSP latency and stimulus rise time could be expected from almost any neuron in the auditory system. However, such a simple
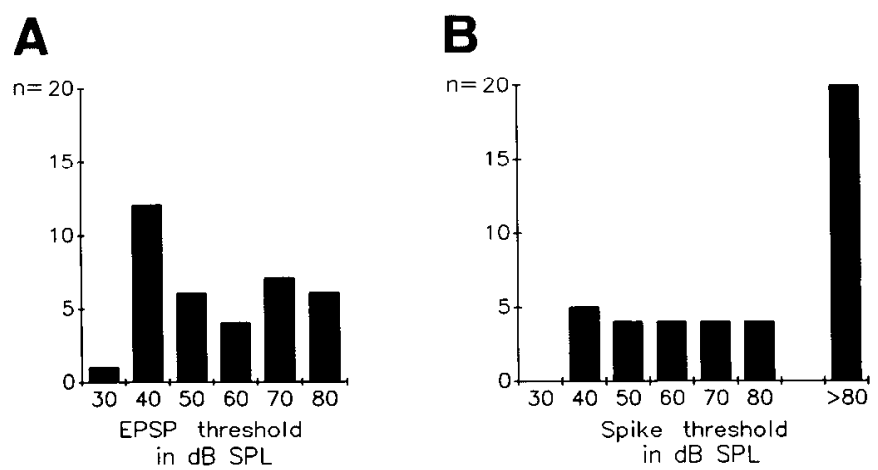

Figure 5. Distribution of EPSP thresholds $(A)$ and spike thresholds $(B)$ of giant PnC neurons. Both EPSP thresholds and spike thresholds are high. Twenty neurons did not generate action potentials at the maximal stimulus intensity of $80 \mathrm{~dB}$ SPL and were therefore grouped into the category $>80$. threshold mechanism cannot account for the changes in the response pattern of both EPSPs and action potentials.

\section{Sensitivity to paired-pulse stimulation (prepulse inhibition)}

Stimuli of low amplitude, when given at an appropriate time interval before the startle-eliciting stimulus, are well known to reduce or even abolish the ASR (Hoffman and Searle, 1965; Hoffman and Ison, 1980; Ison and Hoffman, 1983; Pilz, 1989). This effect is called prepulse inhibition. We tested whether a similar effect can be observed in giant PnC neurons by stimulating eight cells with two acoustic stimuli (pair pulses) at interstimulus intervals between $40 \mathrm{msec}$ and $500 \mathrm{msec}$. At interstimulus intervals shorter than $400 \mathrm{msec}$, the responses to the second pulse were smaller than those to the first pulse, in terms of both EPSP amplitude (Fig. $7 A-C$ ) and spike number (Fig. $7 D-F$ ). The attenuating influence of the paired-pulse stimulation was independent of the duration of the first pulse over the range tested (compare Fig. $7 A, B$ ), but it clearly depended on its amplitude (Fig. $7 C$ ). When the amplitude of the first pulse was $34 \mathrm{~dB}$ lower than that of the second pulse, no effect on the response to the second pulse was observed.

\section{Habituation to repetitive acoustic stimulation}

A characteristic feature of the ASR is a decrease of its amplitude with stimulus repetition, that is, a habituation of the response (Prosser and Hunter, 1936; Moyer, 1963; Leaton, 1976; Davis and File, 1984; Pilz, 1989). In order to test if an analogous phenomenon occurs in giant PnC neurons, we studied the influence of stimulus repetition on the response amplitude. An example of a neuron's response is illustrated in Figure 8. Following a stimulus-free period of $5 \mathrm{~min}$, the ncuron generated action potentials to the first and third stimulus and EPSPs to all subsequent stimuli with decreasing amplitudes (Fig. 8; squares in $B$ depict action potentials). Shorter waiting periods ( $1-4 \mathrm{~min}$ ) 
A
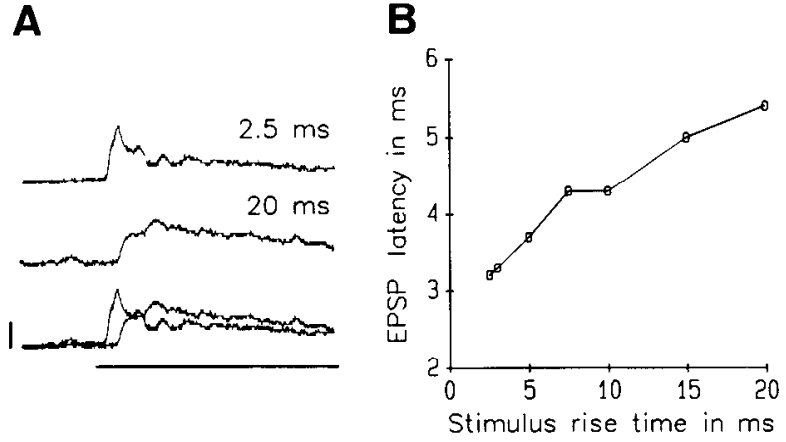

D1

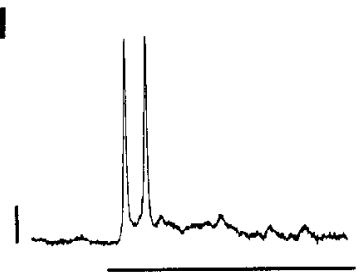

E1

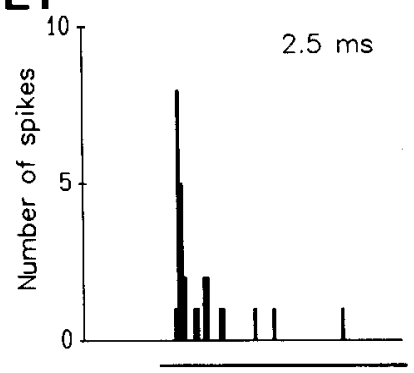

D2

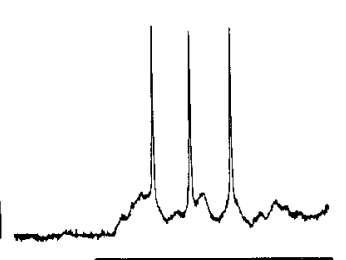

E2

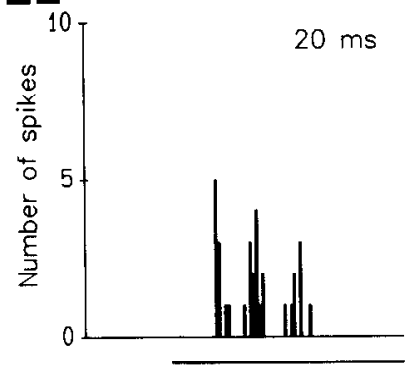

C

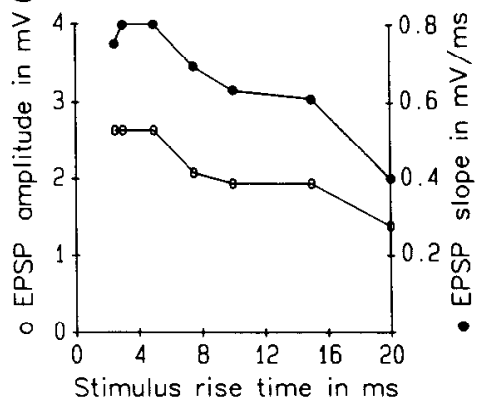

D3

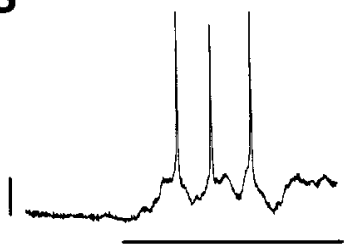

E3

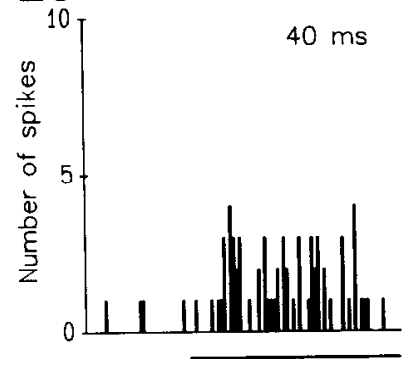

Figure 6. Sensitivity to changes of the stimulus rise time. $A-C$, Effects of the stimulus rise time on the EPSP onset. $A$, Averaged EPSPs elicited by noise pulses with rise times of $2.5 \mathrm{msec}$ (upper trace) and $20 \mathrm{msec}$ (middle trace). Superposition of the two traces is shown in the lower trace. Stimulus duration, $200 \mathrm{msec}$; resting potential, $-64 \mathrm{mV}$. Calibration: $75 \mathrm{msec}, 1 \mathrm{mV} . B$ and $C$, Quantitative analysis the effects shown in $A . B$, Increasing the stimulus rise time increases the EPSP onset latency. $C$, Increasing the stimulus rise time reduces the maximal EPSP amplitude (open cirrles, left vertical axis) and reduces the slope of the EPSP (solid circles, right vertical axis). The slope was calculated for the period between the EPSP onset and the maximal EPSP amplitude. $D$ and $E$, Effects of the stimulus rise time on the spike pattern. $D 1-D 3$, Sequence of action potentials after acoustic stimulation (200 msec pulses) with rise times of $2.5,20$, or $40 \mathrm{msec}$. Calibration: 75 msec, $5 \mathrm{mV}$. E1-E3, PSTHs obtained from the responses shown in $D$ using 20 stimulus presentations. Increasing the stimulus rise time reduces the number of spikes during the on response, while it increases the number of spikes during the tonic response. Calibration, $75 \mathrm{msec}$. had very similar effects (Fig. $8 B$ ), thus showing that the response of giant $\mathrm{PnC}$ neurons does in fact habituate. As the greatest decline of the response was found to the first two or three stimuli of a sequence, the resulting time course of the habituation was similar to that found in the ASR (e.g., Caeser et al., 1989).

It cannot be ruled out that our habituation data may not represent habituation, but rather prepulse inhibition, because we stimulated at a frequency of $1.5 \mathrm{~Hz}$, at which prepulse inhibition can occur. However, two observations support our conclusion that we indeed describe habituation. First, the time course of our data is typical for habituation and was not reported for prepulse inhibition. Second, we did not see attenuating effects in our prepulse inhibition experiments, when stimuli with interstimulus intervals longer than $400 \mathrm{msec}$ were applied. Thus, we will use the expression "habituation" in the following.

\section{Sensitivity to stimulation of the amygdaloid complex}

To clarify the issue of whether giant $\mathrm{PnC}$ neurons receive synaptic input from the amygdala, an important site for fear potentiation of the ASR (summarized in Davis, 1992), we stimulated the amygdaloid complex electrically while recording intracellularly from seven giant $\mathrm{PnC}$ neurons that could be driven acoustically (Fig. 9B1,B2). Six of these responded with shortlatency EPSPs that gave rise to action potentials (Fig. 9A1,A2). The average EPSP onset latency, measured at stimulus intensities near firing threshold, was $2.9 \mathrm{msec}$ (range, $1.6-3.7 \mathrm{msec}$; $N=6$ ) and the maximal EPSP amplitude was reached after 6.1 msec (range, 3.6-10.1 msec). When electrical stimulation of the amygdala was performed in conjunction with acoustic stimu- lation, the resulting response amplitude became larger (Fig. $9(1, C 2)$, indicating that amygdaloid activity enhances the response to acoustic stimuli.

Taken together, the results from our intracellular recordings show that giant PnC neurons receive short-latency, excitatory acoustic input. They have high firing thresholds and broad frequency tuning, and they are sensitive to stimulus rise time and paired-pulse stimulation (prepulse inhibition). Moreover, their responses to repetitive acoustic stimulation habituate and they receive a short-latency, excitatory input from the amygdala (fear potentiation), all of which are features also very characteristic of the ASR. These parallels between the behavior of the animal and the physiological properties of the neurons reinforce the idea that the giant PnC neurons mediate the ASR.

\section{Efferent projections of giant PnC neurons}

In order to analyze the efferent projections of $\mathrm{PnC}$ neurons, we performed anatomical and electrophysiological studies with both intracellularly (HRP) and extracellularly (Fluoro-Gold) applied tracers and antidromic electrical stimulation, respectively. Intracellular injections of HRP into physiologically characterized PnC neurons revealed the axonal morphology of 30 neurons; 15 ncurons with wcll-stained axons were chosen for a detailed analysis and graphically reconstructed. With the remaining 15 neurons we determined their general axonal trajectory without looking at termination sites. An additional neuron was included in our analysis that had a complex axonal morphology but could not be unequivocally identified as a giant $\mathrm{PnC}$ neuron because its cell body was not localized. 
A
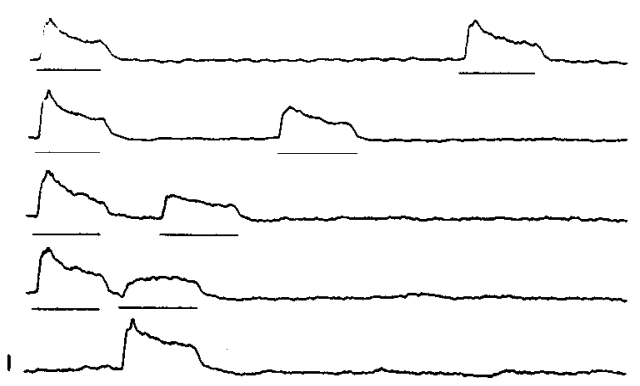

$\mathbf{B}$
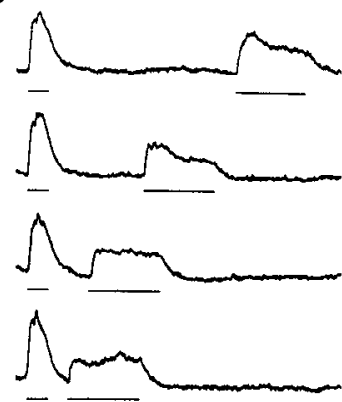

C
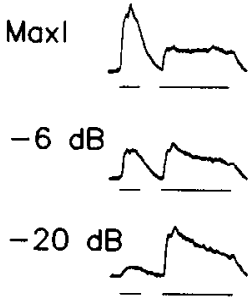

$-34 d B$

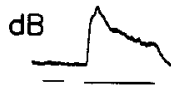

D

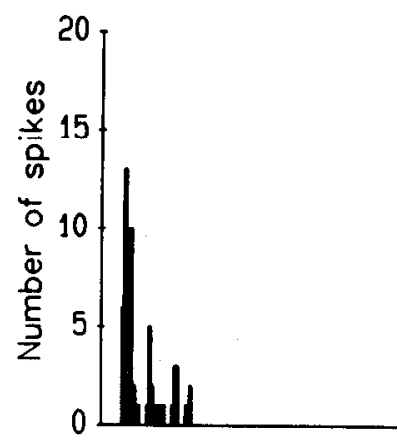

$\mathbf{E}$

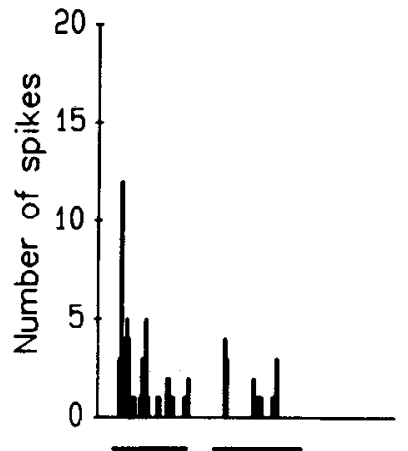

$\mathbf{F}$

Figure 7. Sensitivity to paired-pulse stimulation (prepulse inhibition), $A-C$, Averaged EPSPs following paired-pulse stimulation. $A$ and $B$, Shortening the interstimulus interval between the two pulses decreases the amplitude of the second EPSP. Repetition rate, $0.5 \mathrm{~Hz}$. In $A$, the horizontal bars are $80 \mathrm{msec}$; stimulus intensity was $80 \mathrm{~dB}$ SPL. In $B$, duration of the first pulse (short bars) was 20 msec; duration of the second pulse (long bars) was $80 \mathrm{msec}$. $C$. The attenuating effect of the first pulse can also be seen if its amplitude is lower than that of the second pulse. Duration of the first pulse, $20 \mathrm{msec}$; duration of the second pulse, $80 \mathrm{msec}$; interstimulus time interval, $40 \mathrm{msec}$. $D-F$, Effect of paired-pulse stimulation on the spike pattern (noise stimuli, $80 \mathrm{~dB}$ SPL; duration, 40 msec; interstimulus time interval, $60 \mathrm{msec}$ ).

Of 31 giant PnC ncurons, 28 (90\%) were classificd as reticulospinal cells and had very similar axonal trajectories. Their axons were thick in the vicinity of the cell body (mean diameter, $3.4 \mu \mathrm{m}$ ) and initially projected in the dorsomedial direction before bending and descending ipsilaterally and caudally in the medial longitudinal fascicle. Descending axons could be traced as far as the ventral white matter of the cervical spinal cord (Figs. 10A, 11A), where the HRP reaction product became invisible. Within the medial longitudinal fascicle, up to five firstorder collaterals emerged, generally branched again, and formed axonal arbors, predominantly ipsilaterally. Axonal arbors and terminal structures were seen in the parvocellular reticular nu-
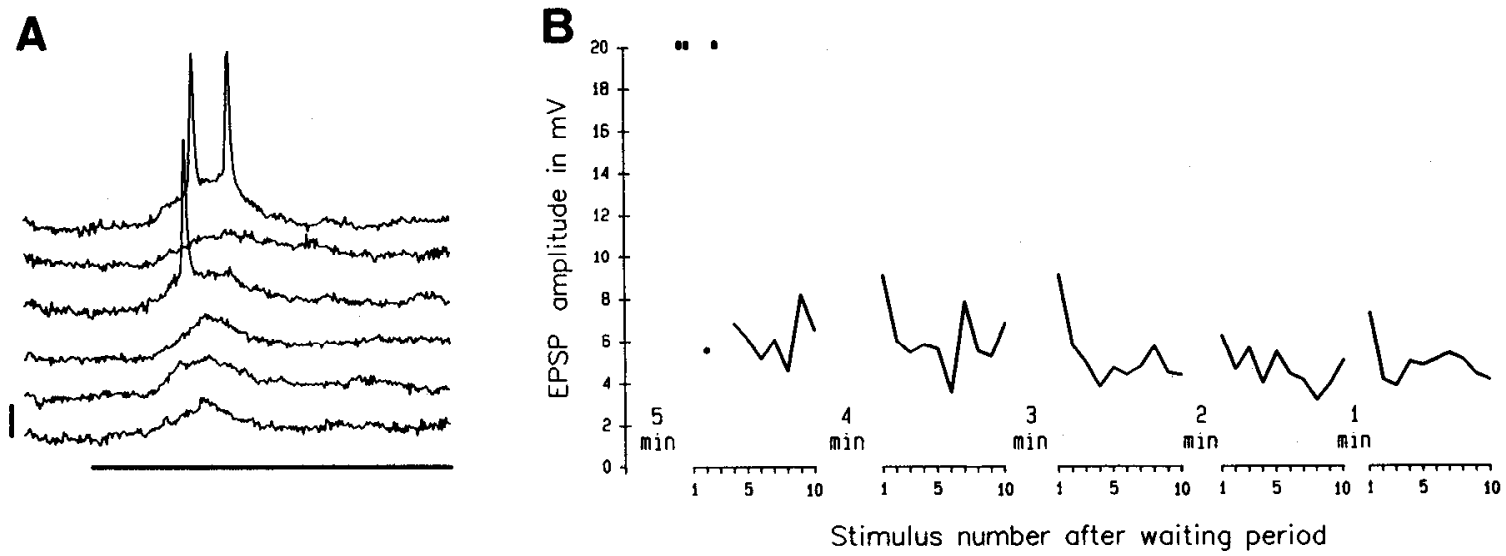

Figure 8. Sensitivity to repetitive acoustic stimulation (habituation). A, Six successive responses (from top to bottom) with decreasing magnitude to acoustic stimulation after a waiting period of $5 \mathrm{~min}$ without acoustic stimulation. Resting potential, $-43 \mathrm{mV}$; stimulus duration, $80 \mathrm{msec}$; repetition rate, $1.5 \mathrm{~Hz}$. Calibration: $5 \mathrm{mV}, 25 \mathrm{msec}$. $B$, Changes in EPSP amplitudes within five trials of stimulus presentations (10 stimuli per trial) after waiting periods of $5,4,3,2$, and $1 \mathrm{~min}$ without acoustic stimulation. Action potentials are indicated by squares in the upper left corner of the diagram. Circle in lower left corner illustrates the EPSP amplitude $(\sim 5.5 \mathrm{mV})$ to the third stimulus within the first trial. 


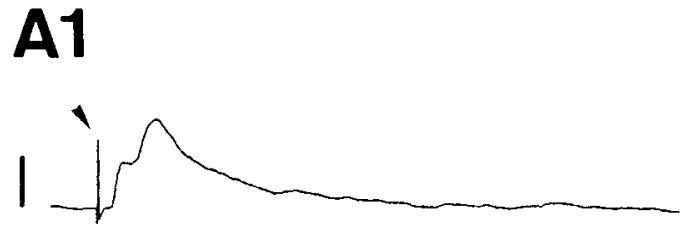

B1

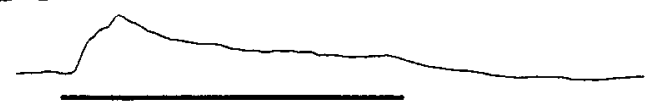

C1

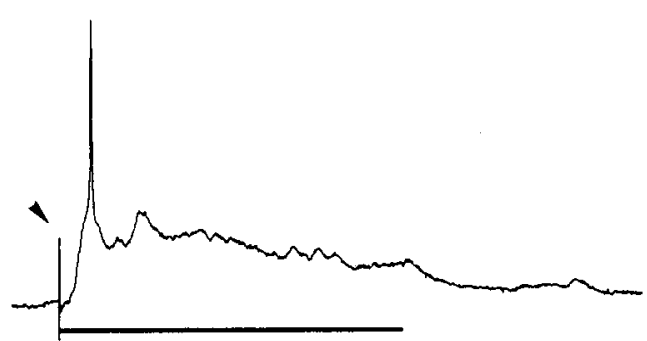

A2

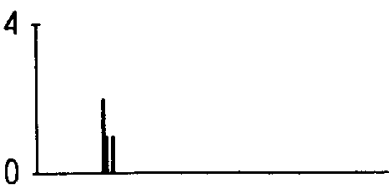

Figure 9. Sensitivity to stimulation of the amygdaloid complex. $A$, Responses to clcctrical stimulation (arrowhead dcpicts stimulus artifact) of the amygdaloid complex around firing threshold. A1, Averaged EPSP of short latency. $A 2$, PSTH after 20 stimulus presentations showing four action potentials. $B$, Responses of the cell shown in $A$ following acoustic stimulation (horizontal bar) straddling firing threshold. $B I$, Averaged EPSP. B2, PSTH after 20 stimulus presentations showing one action potential. $C$, Acoustic stimulation and simultaneous electrical stimulation of the amygdaloid complex. Note that the resulting response is remarkably enhanced. Cl, Suprathreshold EPSP giving rise to an action potential. $C 2$, PSTH after 20 stimulus presentations showing 20 action potentials. Arrowhead points to stimulus artifacts. Calibration: $5 \mathrm{mV}$, $80 \mathrm{msec}$. cleus, the gigantocellular reticular nuclei (alpha and ventralis), the dorsal paragigantocellular nucleus, and the medullary reticular formation. Aside from these reticular projections, axonal arbors and terminals were found bilaterally in the facial nucleus (Fig. $10 B-D$ ) and ipsilaterally close to the hypoglossal nucleus and in the ventral spinal gray matter. Particularly interesting in respect to the ASR were the termination areas within the facial nuclei, which were restricted to the medial aspects of the nuclei (Fig. 10C), that is, to areas where motoneurons for the pinna muscles are located (Friauf and Herbert, 1985). It is well known that the pinna muscles participate in the ASR (Davis and Astrachan, 1978; Caeser et al., 1989).

Aside from the commonly observed reticulospinal trajectory of the axons, two other projection patterns were observed. One type of axon ( $n=2,7 \%$ ) projected on the ipsi- and contralateral side in rostral and caudal directions while giving off numerous collaterals within the mesencephalic, the pontine, and the medullary reticular formation (Fig. $11 B$ ). The caudally projecting axon collaterals did not course in the medial longitudinal fascicle and the neurons could not be activated antidromically by spinal cord stimulation. According to the axonal trajectory, we refer to this type as reticuloreticular. We labeled one neuron whose axon projected in a rostral direction in the medial longitudinal fascicle without giving off collaterals. As the labeling of the main axon faded about $1 \mathrm{~mm}$ rostral to the cell body without forming any terminal fields, the projection pattern remained unclear.

In summary, $90 \%$ (28 of 31 ) of the intracellularly labeled neurons were identified as giant reticulospinal $\mathrm{PnC}$ neurons. According to their axonal course and their thick axonal diameter, these neurons are well suited for transmitting excitation quickly to postsynaptic neurons in the brainstem and the spinal cord. As all of these neurons could be acoustically excited at short latencies, they are able to function as relay neurons between auditory brainstem neurons and spinal motoneurons.

With our intracellular labeling experiments we were unable to identify the termination sites of the giant PnC neurons within the spinal cord. We therefore investigated the efferent projections originating from the $\mathrm{PnC}$ by means of anterograde tracing following injections of PHA-L (Fig. 12). These injections labeled a great number of axonal elements (mean diameter, $3.4 \mu \mathrm{m}$; range, $1.3-7.0 \mu \mathrm{m}$ ) within the white matter of cervical and thoracic levels of the ventral spinal cord (Fig. 13), predominantly on the ipsilateral side. In terms of both their trajectory and their thickness, the PHA-L-labeled axons were strikingly similar to those labeled intracellularly with HRP, thus indicating that axons of giant PnC neurons indeed project as far as thoracic levels of the spinal cord. Often collaterals were seen on the PHA-Llabeled axons that coursed into the spinal gray matter and formed terminal structures, mainly in the ventral horn (laminae V-IX) of the cervical and thoracic spinal cord (Fig. 13). As the cell bodies of spinal motoneurons are located in these areas, the results indicate that reticulospinal $\mathrm{PnC}$ neurons are premotoneurons.

To confirm that at least some of the axonal projections from the $\mathrm{PnC}$ to motoneuron pools in the spinal cord were formed by axons of giant neurons, we stimulated the ventral white matter of the thoracic spinal cord electrically while recording intracellularly from these cells. Seven of 18 giant $\mathrm{PnC}$ neurons tested could be antidromically stimulated, thereby identifying a direct projection from giant $\mathrm{PnC}$ neurons to ventral areas, presumably motoneuron pools, of the thoracic spinal cord. The mean latency of the antidromic action potentials was $1.2 \mathrm{msec}$ (range, 1.1$1.4 \mathrm{msec}$ ). As we always measured the distance between the stimulating and the recording electrodes, we were able to cal- 
Figure 10. Axonal projection pattern of a reticulospinal giant $\mathrm{PnC}$ neuron. Labeling was obtained by intracellular HRP injection into a physiologically characterized neuron. $A$ and $B$, Photomicrographs of axonal details. $A$, Axon segment in the ventral white matter of the spinal cord (sagittal view). $B$, Axon terminals (arrows) in the medial column of the facial nucleus (coronal view). $C$ and $D$, Computer reconstruction of the axonal trajectory as seen if projected onto the coronal plane $(C)$ or the sagittal plane $(D)$. Note bilateral projections and terminal arbors in the facial nuclei and the reticular formation as well as the ipsilateral projection into the spinal cord. Stars indicate the site where the HRP reaction product became invisible. Shaded areas correspond to the extent of the dendritic field of the neuron and dots within the shaded areas illustrate the location of the cell body. The axon of this neuron extended from interaural level -0.8 to the interaural level -6.5 ; when appropriate, interaural levels are shown. 7 , facial nucleus; 12 , hypoglossal nucleus; $C G P n$, central gray of the pons; $C N$, cochlear nuclear complex; $g 7$, genu of the facial nerve; $G i$, gigantocellular reticular nucleus; GiV, gigantocellular reticular nucleus, ventral part; $I O$, inferior olive; $m c p$, middle cerebellar peduncle; $P n$, pontine nuclei; $\mathrm{PnO}$, oral pontine reticular nucleus; $\operatorname{Pr} 5$, principal sensory trigeminal nucleus; $s 5$, sensory root of the trigeminal nerve. Scale bars: $A$ and $B, 50 \mu \mathrm{m} ; C$ and $D, 1 \mathrm{~mm}$.
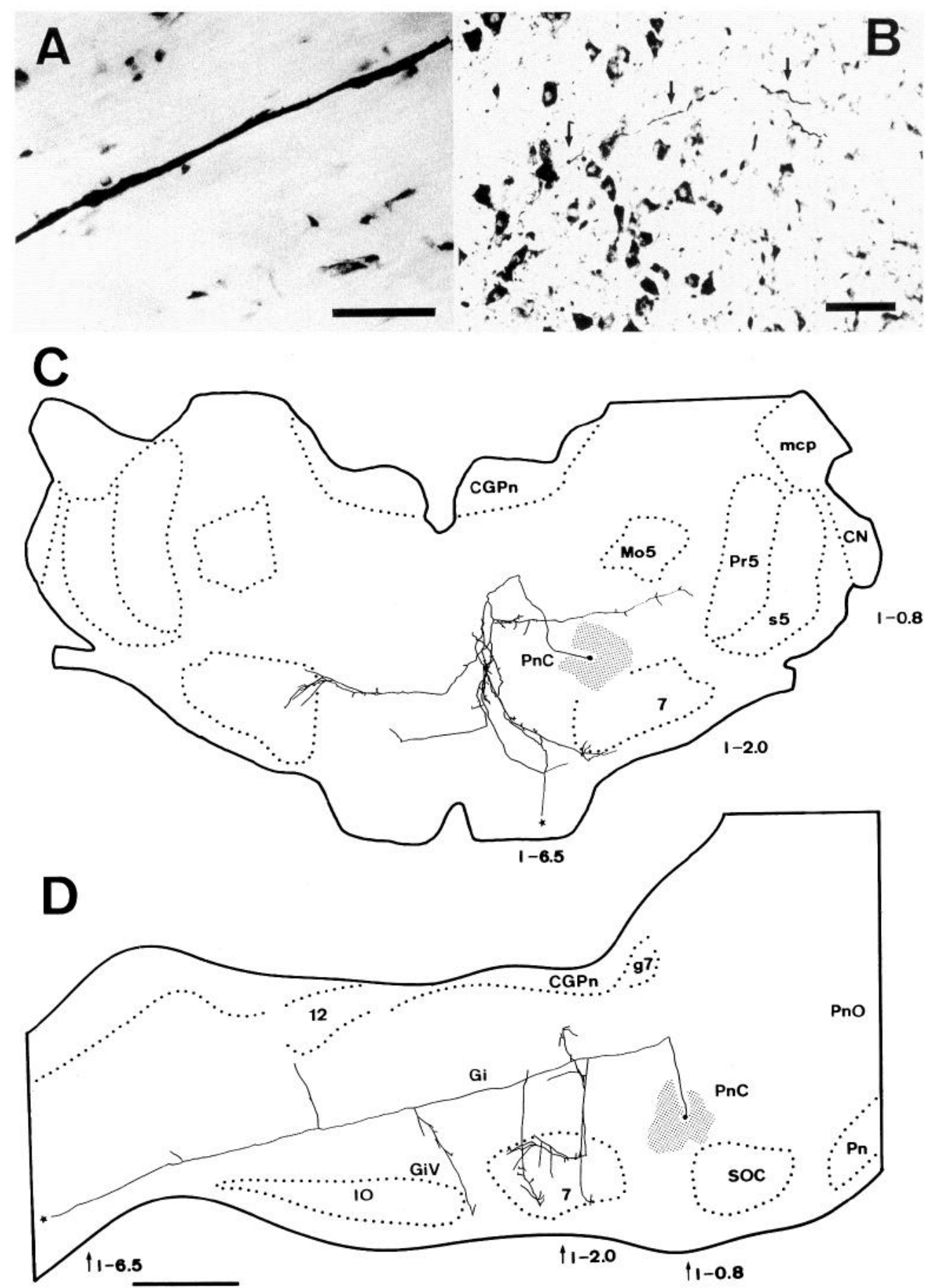

culate the conduction velocity of our sample, which was 49.0 $\mathrm{m} / \mathrm{sec}$ (range, $41.1-54.0 \mathrm{~m} / \mathrm{sec}$ ).

\section{Summary}

Taken together, our results show that giant $\mathrm{PnC}$ neurons are likely candidates for the mediation of acoustically elicited behavior such as the short-latency ASR. These cells enable very quick transmission (within $6.2 \mathrm{msec}$ ) of acoustic information from the periphery to motoneuron pools in the brainstem and the spinal cord. As they receive input from auditory nuclei and in turn project into motoneuron pools, they form a direct linking element in an acousticomotor pathway and, literally, a senso- rimotor interface. All of the tested typical characteristics of the ASR, such as high threshold, sensitivity to stimulus rise time, prepulse inhibition, and habituation, are paralleled by the response properties of giant reticulospinal $\mathrm{PnC}$ neurons. These neurons are therefore in a perfect position to participate in the mediation of the ASR and to form a neuronal substrate for the analysis of behavior in mammals.

\section{Discussion}

A great amount of evidence has already pointed out the PnC's crucial role in the elementary startle circuit (Szabó and Hazafi, 1965; Hammond, 1973; Siegel and McGinty, 1977; Leitner et 

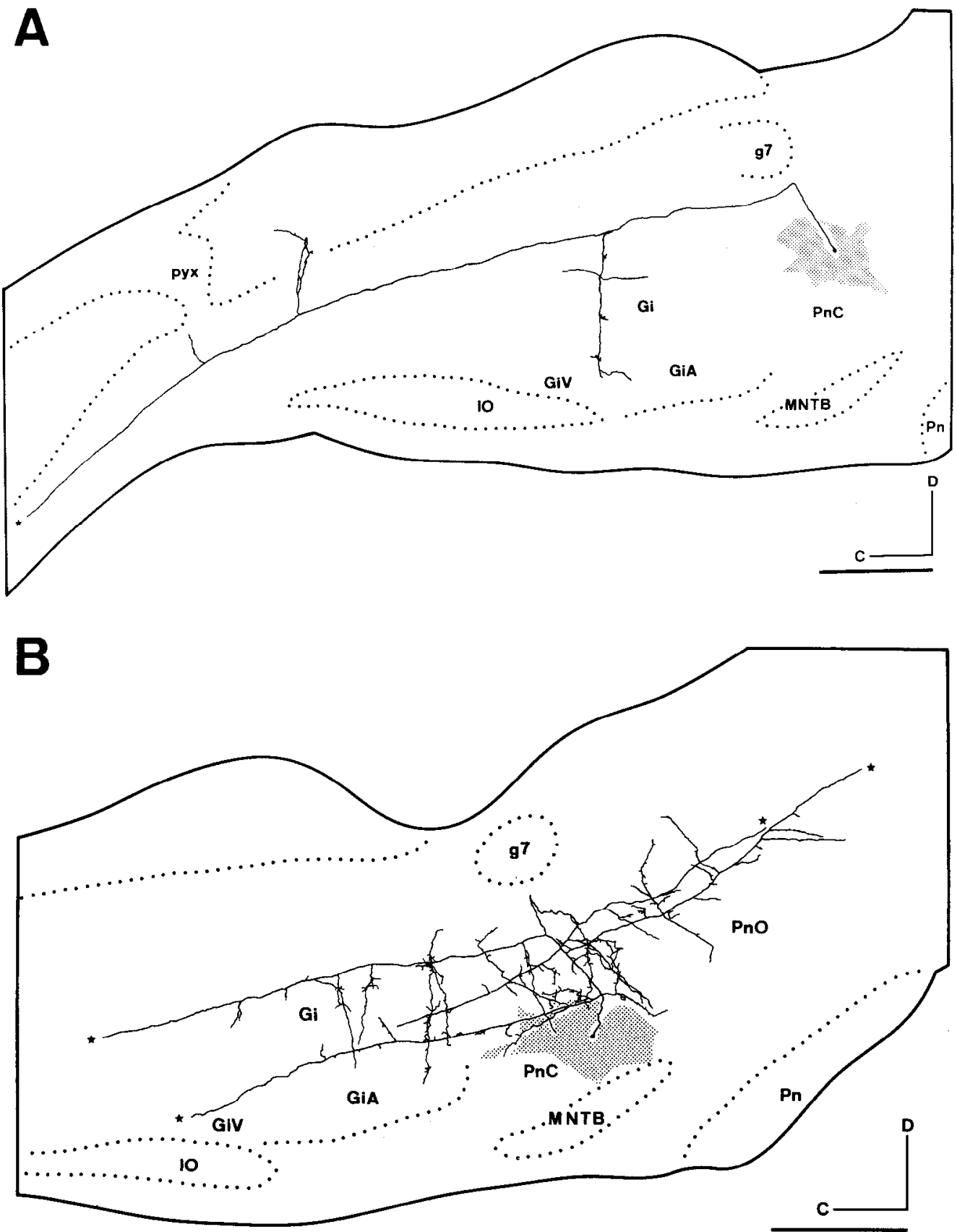

Figure 11. Comparison of the types of axonal projection pattern seen in giant PnC neurons. $A$, Reticulospinal neuron. Terminal axonal arbors are present in the reticular formation, but not in the facial nucleus. $B$, Reticuloreticular neuron. Axon collaterals both descend and ascend within the brainstem and form numerous collateral arbors within the mesencephalic, the pontine, and the medullary reticular formation. Dendritic areas are shaded. Stars indicate the sites where the HRP reaction product became invisible. GiA, gigantocelIular reticular nucleus, pars alpha; $p y x$, pyramidal decussation. Other abbreviations are as for Figure 10. Scale bars, $1 \mathrm{~mm}$.

al., 1980; Davis et al., 1982a; Siegel and Tomaszewski, 1983; Boulis and Davis, 1989; Müller and Klingberg, 1989; Yeomans et al., 1989). In our opinion, the most convincing data have been provided by $\mathrm{Wu}$ et al. (1988), who found a correlation between the ASR and neuronal activity in the $\mathrm{PnC}$, and by Koch et al. (1992), who described a loss of the ASR after axon-sparing lesions with the neurotoxic substance quinolinic acid. Their data revealed a significant correlation between the number of giant $\mathrm{PnC}$ neurons and the amplitude of the ASR, suggesting that these cells form a synaptic relay station in the elementary acoustic startle circuit.

The aim of the present study was to investigate whether giant $\mathrm{PnC}$ neurons fulfill essential physiological and anatomical requirements that would enable them to participate directly in acoustically elicited behavior such as the ASR. Based on our electrophysiological (see Methodological considerations in Materials and Methods) as well as anatomical results, we suggest that these cells act as a direct linking element between sensory neurons and motoneurons. As they receive direct input from neurons in the cochlear nuclear complex and in turn project to motoneuron pools in the brainstem and spinal cord, the elementary startle circuit most likely comprises fewer central relay stations than previously proposed. Indeed, from our data we conclude that there are only three central synaptic stations: neurons in the CRN, giant reticulospinal PnC neurons, and cranial and spinal motoneurons (Fig. 14). The evidence for our proposal of such a short and simple elementary startle circuit will be outlined in the following. We will first concentrate on the physiological properties of the giant $\mathrm{PnC}$ neurons and then discuss their afferent and efferent connectivity. 

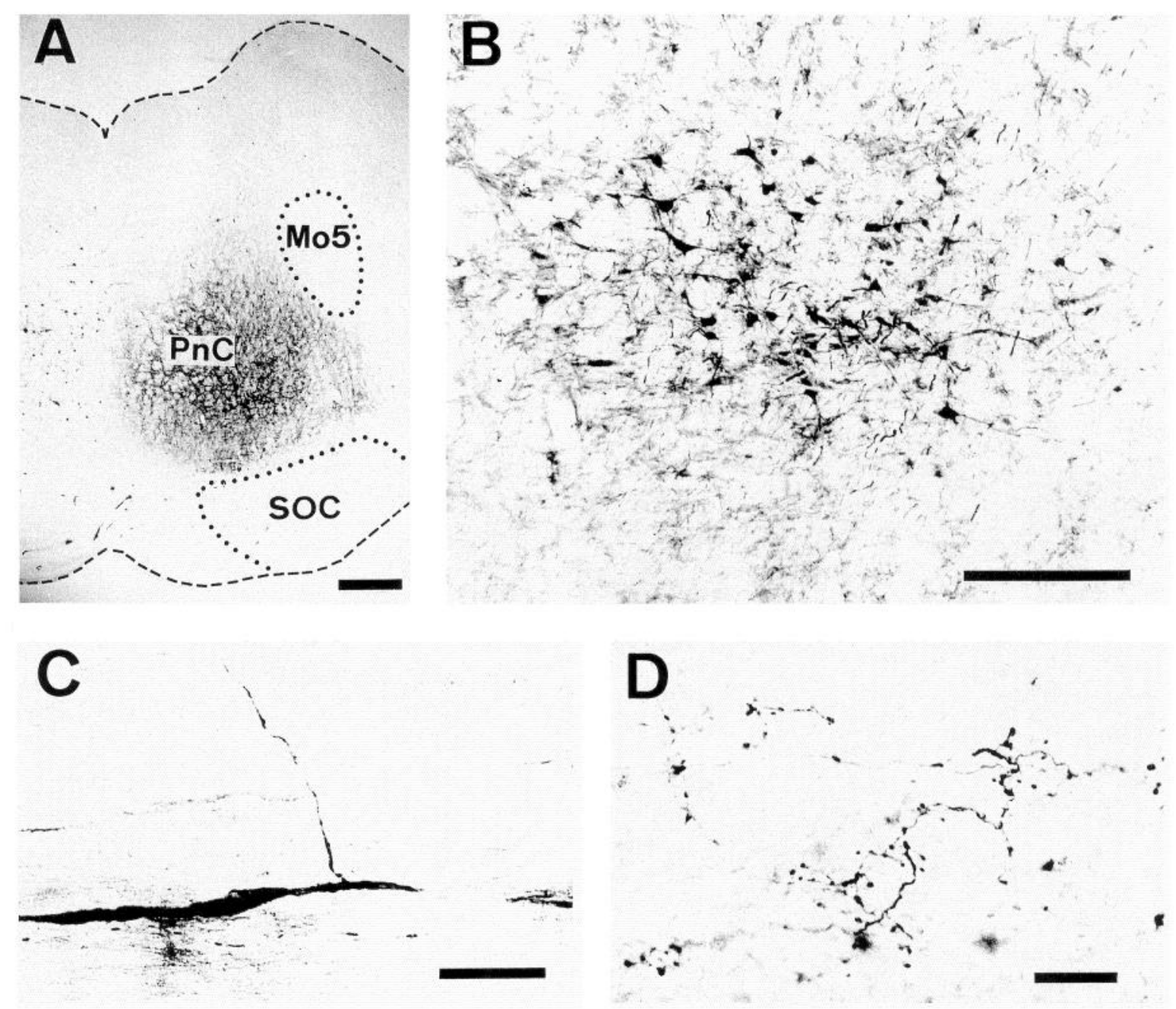

Figure 12. Efferent projections from the $\mathrm{PnC}$ into the reticular formation and the spinal cord. Results were obtained by iontophoretic application of PHA-L into the PnC ( $A$; note lack of spread into Mo5 and SOC). $B$, Same section as in $A$, but under higher magnification, showing the presumptive area of tracer uptake that includes several giant PnC neurons. $C$, Labeled axon in the ventral white matter of the spinal cord, giving rise to a collateral that courses dorsally. Sagittal view; rostral is to the right, and dorsal is to the top. $D$, Terminal axonal arbors with boutons in the ventral gray matter of the spinal cord. Scale bars: $A, 500 \mu \mathrm{m} ; B, 250 \mu \mathrm{m} ; C, 50 \mu \mathrm{m} ; D, 25 \mu \mathrm{m}$.

\section{Giant PnC neurons - a neuronal correlate of the ASR?}

The short EPSP onset latency and spike latency of $2.6 \mathrm{msec}$ and $5.2 \mathrm{msec}$, respectively, that we recorded in giant $\mathrm{PnC}$ neurons in response to noise pulses (Lingenhöhl and Friauf, 1992; present results) were one of the criteria that these cells had to fulfill in order to be able to participate in the ASR. During the course of our study, we found many additional response properties of giant PnC neurons that are also characteristic of the ASR.

High firing thresholds and broad frequency tuning. EPSP thresholds to acoustic stimuli exceeded $60 \mathrm{~dB}$ SPL in almost half of our sample and $50 \%$ of all cells did not generate action potentials when sound intensities of $80 \mathrm{~dB}$ SPL were offered, consistent with results from extracellular recordings (Ebert and Koch, 1992). Spike thresholds of most auditory brainstem neurons are typically much lower (0-30 dB SPL; e.g., Goldberg and Brown, 1969), indicating that giant $\mathrm{PnC}$ neurons have particularly low sensitivity. As the acoustic startle threshold of the rat runs nearly parallel to, and $87 \mathrm{~dB}$ SPL above, the curve of hearing threshold (Pilz et al., 1987), there is a good match be- tween the ASR threshold and the firing threshold of giant $\mathrm{PnC}$ neurons.

Sensitivity to stimulus rise time. The shape of the acoustic stimulus is known to influence the ASR (Fleshler, 1965; Marsh et al., 1973). Both the amplitude and latency of the ASR are affected by the stimulus rise time: reducing the rise time increases the ASR amplitude and decreases its latency (Pilz, 1989). Very similar effects are also observed in giant PnC neurons; for example, spike latencies decreased more than threefold when the stimulus rise time was decreased from $40 \mathrm{msec}$ to $2.5 \mathrm{msec}$. In contrast, the tonic response could even be increased when stimuli with successively longer rise times were used, in contrast to the effect observed on the ASR. These data indicate that the magnitude of the onset response, rather than the spike activity during the tonic response, is relevant for the primary ASR. Furthermore, synchronous onset activity in giant $\mathrm{PnC}$ neurons, as observed with short rise times, will more likely result in suprathreshold excitation in motoneurons (due to spatial and temporal summation phenomena), which is essential to elicit an ASR. 

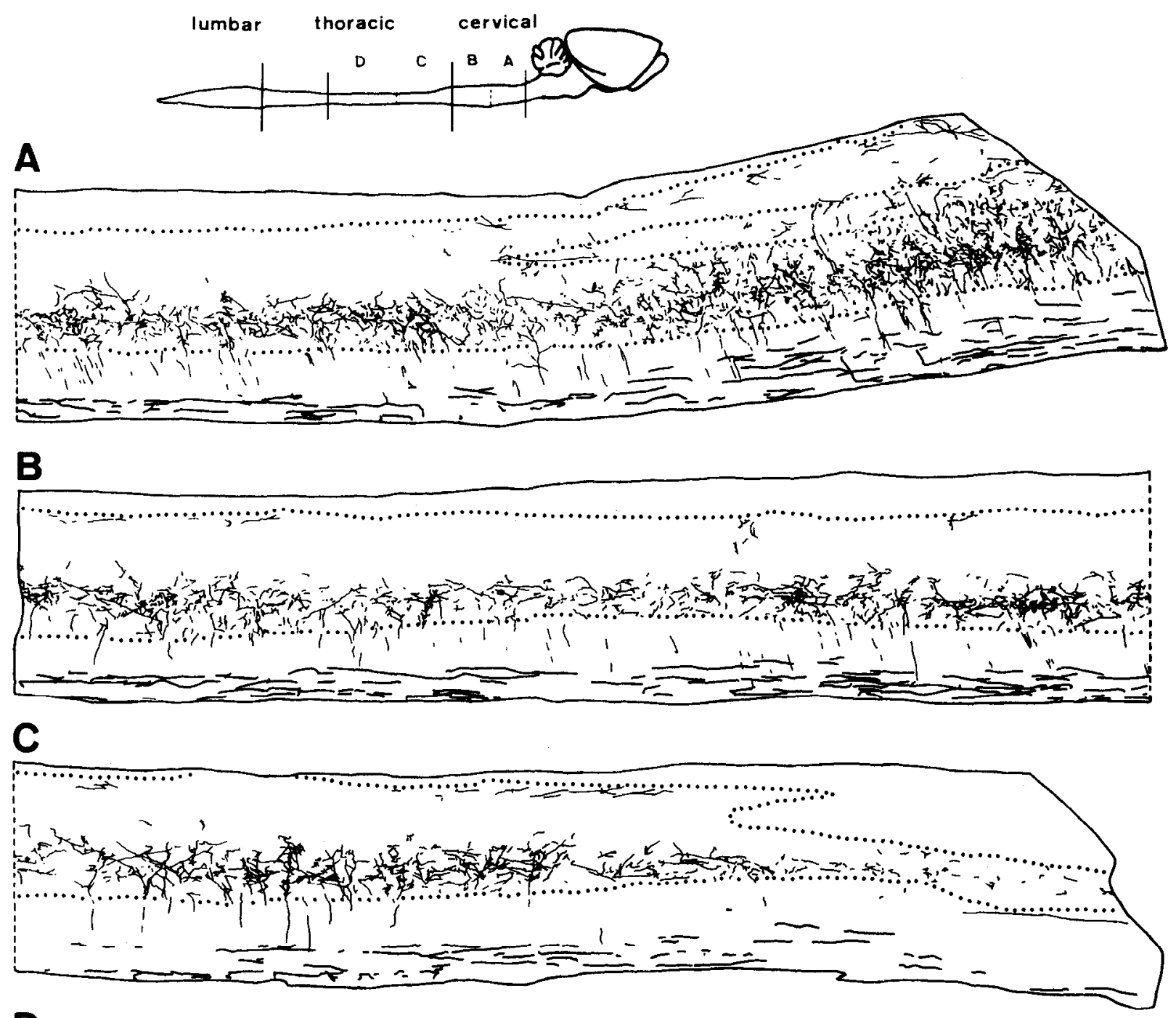

D

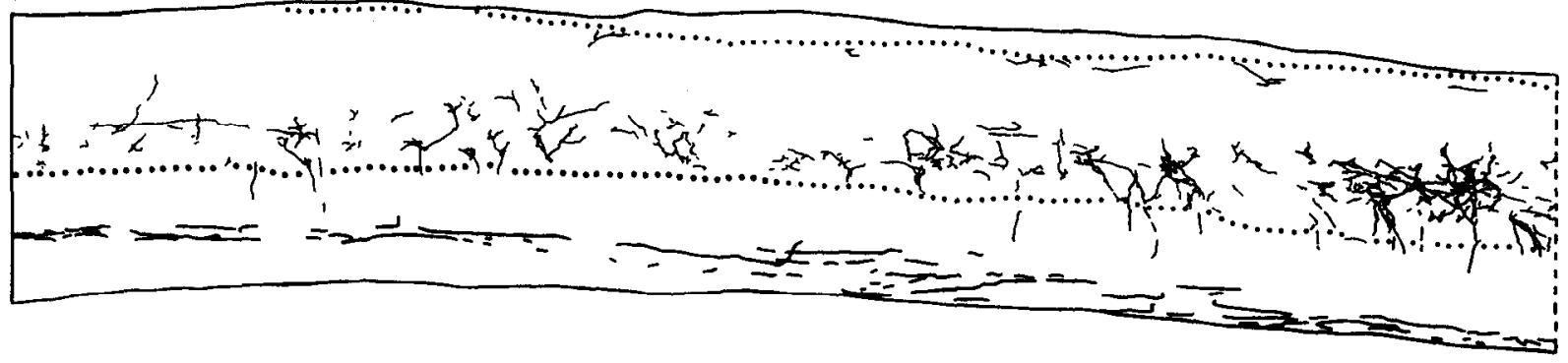

Figure 13. Camera lucida drawings of PHA-L-labeled axons and terminal structures in the spinal cord ipsilateral to the injection site. The spinal cord was cut into three parts, roughly corresponding to the cervical, thoracic, and lumbar regions. These parts were cut sagittally, and sections from the cervical (labeled $A, B$ ) and the thoracic regions (labeled $C, D$ ) are illustrated (see low-power drawing at the top for their approximate location in the spinal cord). Rostral is to the right and dorsal to the top. Dotted lines surround the gray matter. Scale bar, $1 \mathrm{~mm}$.

Sensitivity to paired-pulse stimulation. Prepulse inhibition of the ASR has been thoroughly investigated (Hoffman and Searle, 1965; Hofmman and Ison, 1980; Ison and Hoffman, 1983; Pilz, 1989) and we found a corresponding phenomenon in the response pattern of giant PnC neurons; that is, we observed an effect of the interstimulus interval on the EPSP amplitude that resembled the effect on the startle amplitude. However, since different stimulus parameters were used (e.g., $10 \mathrm{msec}$ vs 80 msec prepulse duration, with and without background stimulation), one should be careful when attempting to compare directly the behavioral and electrophysiological results. Nevertheless, the response of giant $\mathrm{PnC}$ neurons is attenuated by paired-pulse stimulation, and prepulse inhibition is therefore likely to occur at the synapses onto giant $\mathrm{PnC}$ neurons or even earlier, but not in the spinal cord. This assumption is in agreement with results from extracellular recordings that also dem- 


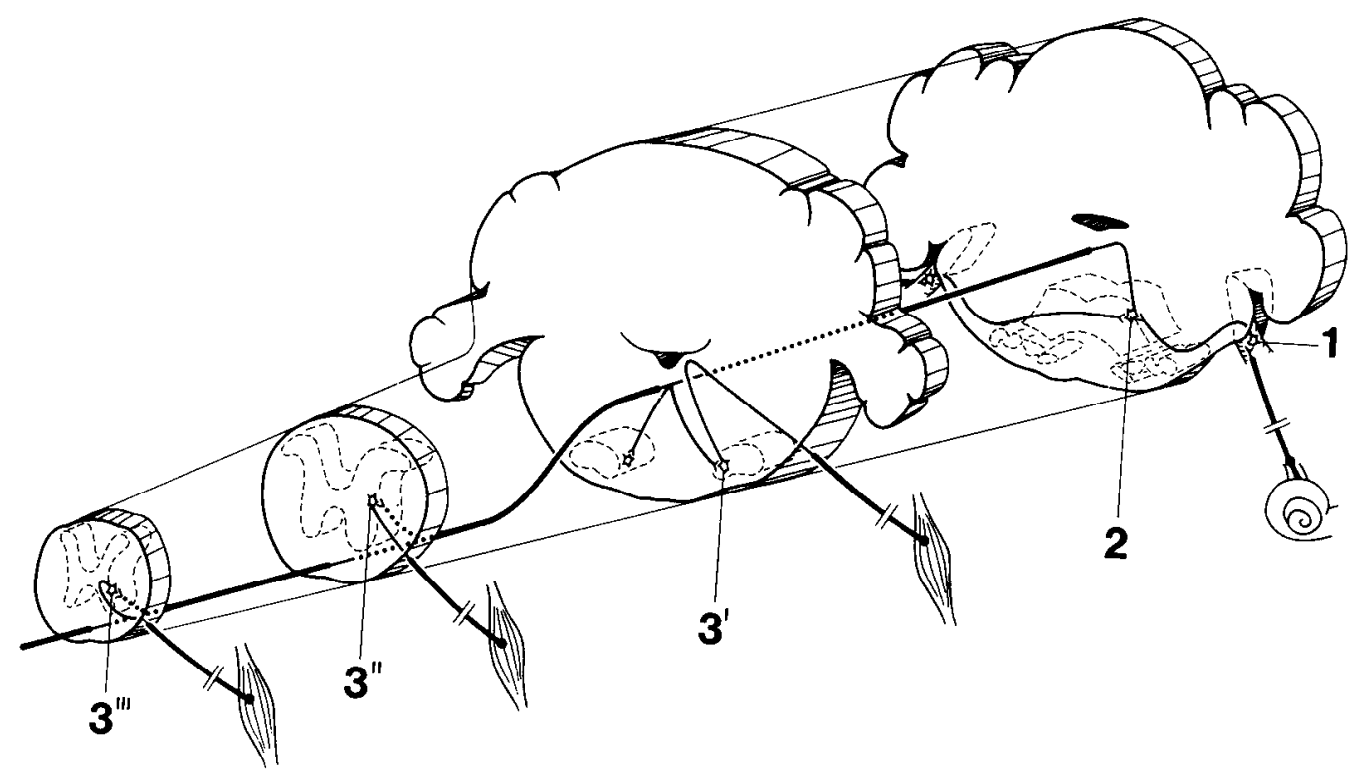

Figure 14. Schematic diagram of the presumptive elementary acoustic startle circuit in the rat brainstem as suggested by our anatomical and electrophysiological results. The proposed circuit comprises only three central relay stations: CRN neurons (I), which receive direct input from auditory nerve fibers; giant reticulospinal PnC neurons (2); and cranial (3') and spinal motoneurons ( $\left.3^{\prime \prime}, 3^{\prime \prime \prime}\right)$.

onstrated the inhibitory effect of prepulse stimulation on the spike activity of PnC neurons (Wu et al., 1988). As we never observed IPSPs in our recordings, it is possible that presynaptic inhibition may occur in the PnC. Alternatively, auditory input neurons to giant PnC cells may already be sensitive to pairedpulse stimulation.

Habituation to repetitive acoustic stimulation. The ASR shows habituation to a repeated acoustic stimulus and we found an equivalent in giant PnC neurons. Neurons in the pontomedullary reticular formation have previously been reported to habituate to repetitive sensory stimulation (Peterson et al., 1976), and the most effective stimulus rates of $0.25-2 \mathrm{~Hz}$ described by these authors are well matched by our parameters $(1-1.5 \mathrm{~Hz})$. As habituation in giant $\mathrm{PnC}$ neurons occurred during the first stimuli within a trial and did not abolish the response completely, it is clear that most of our electrophysiological data are not distorted by dynamic habituating effects, because they were obtained when a steady state response was present. Again, it would be interesting to know whether the habituation occurs at the level of giant PnC neurons or before. The latter possibility was favored by Peterson et al. (1976), particularly due to the observation that the spontaneous activity of pontomedullary neurons did not change under conditions of habituation, indicating that these neurons do not receive direct, long-lasting inhibition that may depress their response. As electrical stimulation of the cochlear nuclear complex but not the reticular formation also results in habituation of the startle-like response (Davis et al., 1982b), it is very likely that the synapse between cochlear nuclear complex neurons and giant $\mathrm{PnC}$ cells is prone to habituation.

Sensitivity to stimulation of the amygdaloid complex. Aversive stimuli presented to the animals are known to increase the amplitude of the ASR. This effect is called fear potentiation (Brown et al., 1951; Davis et al., 1991). It has been shown that the amygdaloid complex is involved in fear potentiation (reviewed in Davis, 1992), that there is a direct projection from the amygdaloid complex into the PnC (Rosen et al., 1991; Koch and
Ebert, 1993), and that electrical stimulation of the amygdaloid complex enhances the startle response (Rosen and Davis, 1988, 1990). Our data show that there is an excitatory projection from the amygdaloid complex to giant $\mathrm{PnC}$ neurons, but the latency ( 2.9 msec to EPSP onset, 6.1 msec to EPSP maximum) does not necessarily suggest a direct, monosynaptic pathway. Moreover, our results that show that single electric shocks can elicit long-lasting EPSPs and bursts of action potentials in giant $\mathrm{PnC}$ neurons, point to the possible involvement of additional neuronal elements. These elements are likely to mediate excitation into the $\mathrm{PnC}$ by several parallel pathways that finally converge on giant $\mathrm{PnC}$ neurons.

\section{Auditory afferents into the $P_{n} C$}

The results from our Fluoro-Gold tracing experiments showed that the greatest number of labeled input neurons were located in the DCN, followed by the LSO and the VCN. About $1 \%$ of the tolal auditory input originated from neurons in the CRN and only a negligible number of labeled neurons were seen in the NLLs. These findings are in contrast to previous results (Davis et al., 1982a) that identified the dorsal NLL as the only auditory nucleus giving rise to input into the PnC. However, our results are consistent with those of Shammah-Lagnado et al. (1987), who also did not see a projection from the NLLs into the PnC. Consequently, our data and those of Shammah-Lagnado and colleagues do not support the conclusion that the ventral and/or dorsal NLL are a synaptic link in the elementary startle circuit, as has been previously hypothesized (Davis et al., 1982a, 1986).

The idea that the NLLs do not play a substantial role in the elementary startle circuit is further corroborated by the fact that the relatively long response latencies of NLL neurons (4.4-7.4 msec; Preuß, 1991) do not fit with the very short electromyographic latencies (5-6 msec; Hammond et al., 1972; Cassella et al., 1986; Pilz et al., 1988; Rosen and Davis, 1988; Caeser et al., 1989; Pellet, 1990) reported for the ASR in head and neck muscles. We did, however, retrogradely label neurons in the 
ventrolateral tegmental nucleus (VLTg), an area immediately ventromedial to the ventral NLL. The VLTg is known to receive input from the VCN (Kandler and Herbert, 1991; Klepper and Herbert, 1992) and to project into the PnC (Klepper and Herbert, 1992), and startle-like responses appear to be mediated by the VLTg (Frankland and Yeomans, 1992). Thus, it is conceivable that this nucleus also forms an important synaptic relay station in the ASR circuit. Nevertheless, we favor the idea that direct axonal projections from neurons within the cochlear nuclear complex provide an input to the PnC that is sufficient for eliciting a primary ASR. Despite the high number of DCN neurons that project into the $\mathrm{PnC}$, these cells are unlikely to participate in the primary ASR, as the long response latencies in the DCN (4-14 msec; Yajima and Hayashi, 1989) are incompatible with the average EPSP onset latency of $2.6 \mathrm{msec}$ in giant $\mathrm{PnC}$ neurons. This assumption is fully in line with results showing that clectrolytic lesions of the DCN fail to abolish the shortlatency ASR (Davis et al., 1982a). Nonetheless, our present results demonstrate that $\mathrm{DCN}$ neurons exert an excitatory input onto giant $\mathrm{PnC}$ neurons and, therefore, we conclude that the DCN may well have a modulating effect on the ASR, which in fact may be quite a strong effect due to the high number of input neurons. For the same reasons, a modulating effect on the ASR may also be altributed to LSO neurons.

Nine percent of the total number of Fluoro-Gold-labeled auditory input neurons to the $\mathrm{PnC}$ were located in the $\mathrm{VCN}$, with neither the anterior nor the posterior division being particularly dominant. Response latencies of rat VCN neurons $(2.2-2.6 \mathrm{msec}$; Friauf and Ostwald, 1988) are sufficiently short to account for ASR latencies, thereby suggesting that VCN neurons could be involved in the ASR, which is consistent with the report that electrolytic lesions of the posterior VCN abolish the ASR and that electrical stimulation of this area elicits an ASR-like response (Davis et al., 1982a). However, following injections of the anterograde tracer PHA-L into the $\mathrm{VCN}$, only very few axon collaterals were seen in the PnC (Kandler and Herbert, 1991), indicating that VCN neurons have only weak terminal arbors in the PnC. This conclusion is further corroborated by the results of intracellular HRP injections into VCN neurons, which demonstrated axon collaterals, but no prominent terminal arbors, within the PnC (Friauf and Ostwald, 1988). Taken together, these data reinforce the idea that the VCN plays no significant role in the elementary ASR circuit.

\section{$C R N$ as a synaptic relay in the ASR?}

Neurons within the CRN, which is also called the "acoustic nerve nucleus" (Harrison et al., 1962), were consistently labeled by our Fluoro-Gold injections into the $\mathrm{PnC}$, yet their contribution to the total number of auditory input neurons was very small (only 1\%). Initially, this result seemed to conflict with the possible role of these neurons in the mediation of the ASR. Nevertheless, we continue to consider these multipolar cells the most likely candidates among neurons of the cochlear nuclear complex, due to a variety of reasons. First, it is important to consider that the total number of CRN neurons, which appear to form a single morphological class (Ilarrison et al., 1962; Merchán et al., 1988), is quite low in the rat: reported numbers are 122 (range, 76-146; Harrison and Irving, 1966) and 40-50 (Merchán et al., 1988). Second, CRN neurons most likely receive direct input from auditory nerve fibers, because all synaptic endings on the cells disappeared after destruction of the auditory nerve (Harrison et al., 1962; Harrison and Irving, 1966). Syn- aptic endings, consisting of terminal boutons, are present in large numbers (Harrison and Irving, 1966) and resemble those arising from auditory nerve fibers (Merchán et al., 1988). Terminal boutons mainly contact the soma and cover $37-47 \%$ of its surface (Merchán et al., 1988), suggesting that synaptic transmission is fast, reliable, and powerful. Interestingly, the vast majority of axosomatic boutons contain round vesicles and form asymmetric synapses (Merchán et al., 1988), providing evidence of excitatory input. Third, the peripheral location of the CRN indicates that its neurons receive auditory input earlier than all other cells in the auditory pathway (e.g., cells in the VCN), which is in full agreement with the very short EPSP latencies $(2.6 \mathrm{msec})$ of giant PnC neurons. Fourth, CRN neurons have thick soma diameters $(\sim 35 \mu \mathrm{m}$; Harrison and Irving, 1966; Ross and Burkel, 1971; Merchán et al., 1988) and appear to be the largest cells of the cochlear nuclear complex (Harrison and Warr, 1962). They give rise to myclinated, large-diameter axons $(3.7 \mu \mathrm{m}$; Harrison and Irving, 1966; Merchán et al., 1988), strongly suggesting that they have fast-conducting axonal properties. Some of their dendrites are clearly oriented across the auditory nerve fibers (Merchán et al., 1988), indicating that they receive input from a broad frequency range. The transmitter phenotype of CRN neurons has not been identified as yet, but they do not contain the inhibitory transmitters glycine and GABA (Kolston et al., 1992) or ACh (Yao and Godfrey, 1992). Thus, it is well conceivable that they use glutamate or another excitatory transmitter, which one should expect if they play a role in eliciting the ASR. The latter assumption is in accordance with recent data demonstrating that the short-latency acoustic input to $\mathrm{PnC}$ neurons is mediated by glutamate receptors of the AMPA/kainate subtype (Ebert and Koch, 1992). Finally, it is worthwhile to review the histology and extent of the lesions in the posterior VCN that Davis et al. (1982a) successfully produced in order to abolish the ASR. From their published data (see their Fig. 3) it can be inferred that even their smallest lesions were located remarkably ventral in the cochlear nuclear complex and clearly involved areas that are occupied by the ventral acoustic stria. CRN neurons have been reported to send their axons into the ventral acoustic stria (Harrison and Irving, 1966; Merchán et al., 1988; López et al., 1993), and therefore it is quite possible that Davis et al. (1982a) in fact destroyed their output fibers as well.

Anterograde tracing studies are certainly necessary to determine the target nuclei of CRN neurons and to address the question of whether these cells contribute a substantial auditory input to the PnC. Interestingly, preliminary studies employing PHA-L injections into the CRN have yielded the first evidence that axon arbors of its neurons do indeed terminate in close vicinity to somata of giant PnC neurons (D. E. López, personal communication), and the perisomatic terminals are indicative of a fast and very powerful auditory input onto giant $\mathrm{PnC}$ neurons. Clearly, further studies on CRN neurons are necessary to elucidate their potential role in the ASR. Nevertheless, all the above-mentioned characteristics of CRN neurons are in line with the idea that they form the first central relay station in the clementary startle circuit.

\section{Efferent projections of giant PnC neurons}

Reticulospinal projections. Ninety percent of our sample of intracellularly labeled giant PnC neurons had thick axons that projected ipsilaterally into the spinal cord (reticulospinal neurons). A similar projection pattern was earlier observed in neu- 
rons of the cat gigantocellular tegmental field (Grantyn et al., 1987, 1992; Mitani et al., 1988a), which corresponds to the PnC (Hammond, 1973; see also Lingenhöhl and Friauf, 1992). Although we could not trace the axons of giant $\mathrm{PnC}$ cells beyond the level of the cervical spinal cord, the results of our PHA-L tracing experiments show that axonal projections from $\mathrm{PnC}$, neurons extend into thoracic levels of the spinal cord and form terminal arbors in areas containing motoneuron pools, thus confirming previous reports in rats (Jones and Yang, 1985; Newman, 1985) and cats (Tohyama et al., 1979; Holstege and Kuypers, 1982; Mitani et al., 1988b). Moreover, our antidromic stimulation experiments identified giant $\mathrm{PnC}$ neurons as a source of these descending projections and also demonstrated that they have fast axon conduction velocities (about $50 \mathrm{~m} / \mathrm{sec}$ ), as has been previously proposed (Yeomans et al., 1989). In the cat, conduction velocities of $40-110 \mathrm{~m} / \mathrm{sec}$ have been reported (Mitani et al., 1988a; Grantyn et al., 1992).

Two of 31 giant $\mathrm{PnC}$ neurons had terminal axon arbors bilaterally in the facial nucleus. The restriction of these arbors to the medial column is interesting because motoneurons to the pinna muscles are located here (Friauf and Herbert, 1985). Some of the giant $\mathrm{PnC}$ neurons may consequently participate in transmitting acoustic information to cranial motoneurons that are involved in the ASR (Pilz et al., 1988; Caeser et al., 1989; Pellet, 1990) or the pinna reflex (Cassella and Davis, 1986). We did not see projections into the motor trigeminal nucleus (Mo5), whose motoneurons also innervate muscles (e.g., the temporal and masseter) that are involved in the ASR (Pilz et al., 1988; Caeser et al., 1989). As these muscles begin to contract about $1 \mathrm{msec}$ later than pinna muscles (Caeser et al., 1989), it is possible that an additional synaptic relay station in the reticular formation is involved. The identity of this relay station is completely unclear at present.

Taken together, our findings that giant $\mathrm{PnC}$ neurons send out fast-conducting axons, which project into areas containing cranial and spinal motoneurons, lend further credence to the assumption that they act as a sensorimotor interface in the ASR.

Reticuloreticular projections. Reticuloreticular neurons with bilateral axon arbors formed only a minority in our sample, corroborating similar results in the cat (Mitani et al., 1988a). As to the function of these neurons, one can only speculate that they may participate in one or another context attributed to the reticular formation (e.g., REM sleep, arousal, locomotion, pain; for summary, see Siegel, 1979).

\section{A short elementary startle circuit of only three central relay stations?}

As outlined above, $\mathrm{CRN}$ neurons are in a perfect position to transmit short-latency acoustic input to giant $\mathrm{PnC}$ neurons and they may, therefore, participate in the ASR. In addition, giant reticulospinal PnC neurons are likely presynaptic to cranial and spinal motoneurons that also participate in the ASR. Based on these and all the other presently available data, we propose an elementary acoustic startle circuit that comprises the following elements: auditory nerve fibers, CRN neurons, giant reticulospinal PnC neurons, and cranial and spinal motoneurons (Fig. 14). This circuit encompasses only three central synaptic relay stations and is thus shorter and less complex than previously suggested (Davis et al., 1982a).

Startle circuits show a convergent evolution in the reduction of the number of synaptic conncctions between sensory neurons and motoneurons in diverse invertebrate phyla (reviewed in
Eaton, 1984). This reduction is also evident in lower vertebrates where startle is mediated by a well-described circuit. Given that the brainstem has a common genetic basis in vertebrates and is the most highly conserved region of the vertebrate brain, it is not surprising that the elementary acoustic startle circuit of rats comprises only three central relay stations.

\section{Conclusions}

The present study has characterized brainstem neurons that most likely are involved in the mediation of acoustically induced behavior such as the ASR. As these neurons form a sensorimotor interface in a short circuit that is likely to be composed of only three central synapses and mediates a reflex-like response, they are an appropriate substrate for investigating the neuronal basis of behavior in mammals. The fact that electrophysiological characterization of these neurons can be combined with morphological verification (by means of intracellular recordings and dye injections) offers the possibility of analyzing the neuronal mechanisms of mammalian behavior even at the level of individual, identified neurons. In conclusion, we think that there is a good chance of using the giant $\mathrm{PnC}$ neurons as a useful model for elucidating the neuronal mechanisms that underlie habituation, sensitization, prepulse inhibition, and other types of plasticity observed in the startle response. Further studies on the pharmacology of synaptic transmission and the interplay of convergent synaptic inputs are necessary in order to achieve this goal.

Note added in proof: After this article had been accepted, a report by Miserendino and Davis (1993) appeared, in which the authors mention that the depression of startle found after local infusion of glutamate antagonists near the ventral NLL probably resulted from spread of the drugs to the nearby $\mathrm{PnC}$. This report therefore corroborates our conclusion that the ventral NLL plays no major role in the elementary ASR circuit.

\section{References}

Andrezik JA, Beitz AJ (1985) Reticular formation, central gray and related tegmental nuclei. In: The rat nervous system, Vol 2, Hindbrain and spinal cord (Paxinos G, ed), pp 1-28. Sydney: Academic.

Berod A, Hartman BK, Pujol JF (1981) Importance of fixation in immunohistochemistry. J Histochem Cytochem 29:844-850.

Boulis NM, Davis M (1989) Footshock-induced sensitization of electrically elicited startle reflexes. Behav Neurosci 103:504-508.

Brown JS, Kalish HI, Farber IE (1951) Conditioned fear as revealed by magnitude of startle response to an auditory stimulus. J Exp Psychol 41:317-328.

Caeser M, Ostwald J, Pilz PKD (1989) Startle responses measured in muscles innervated by facial and trigeminal nerves show common modulation. Behav Neurosci 103:1075-1081.

Caicedo A, Herbert H (1993) Topography of descending projections from the inferior colliculus to auditory brainstem nuclei in the rat. $J$ Comp Neurol 328:377-392.

Cassella JV, Davis M (1986) Habituation, prepulse inhibition, fear conditioning, and drug modulation of the acoustically elicited pinna reflex in rats. Behav Neurosci 100:39-44.

Cassella JV, Harty TP, Davis M (1986) Fear conditioning, pre-pulse inhibition and drug modulation of a short-latency startle response measured electromyographically from neck muscles in the rat. Physiol Behav 36:1187-1191.

Crow T (1988) Cellular and molecular analysis of associative learning and memory in Hermissenda. Trends Neurosci 11:136-142.

Davis M (1984) The mammalian startle response. In: Neural mechanisms of startle behavior (Eaton RC, ed), pp 287-351. London: Plenum.

Davis M (1992) The role of the amygdala in fear and anxiety. Annu Rev Neurosci 15:353-376.

Davis M, Astrachan DI (1978) Conditioned fear and startle magni- 
tude: effects of different footshock and backshock intensities used in training. J Exp Psychol [Anim Behav] 4:95-103.

Davis M, File SE (1984) Intrinsic and extrinsic mechanisms of habituation and sensitization: implications for the design and analysis of experiments. In: Habituation, sensitization and behavior (Peeke HVS, Petrinovich L, eds), pp 287-323. New York: Academic.

Davis M, Gendelman DS, Tischler MD, Gendelman PM (1982a) A primary acoustic startle circuit: Lesion and stimulation studies. J Neurosci 2:791-805.

Davis M, Parisi T, Gendelman DS, Tischler MD, Kehne JH (1982b) Habituation and sensitization of startle reflexes elicited electrically from the brainstem. Science 218:688-690.

Davis M, Commissaris RL, Cassella JV, Yang S, Dember L, Harty TP (1986) Differential effects of dopamine agonists on acoustically and electrically elicited startle responses: comparison to effects of strychnine. Brain Res 371:58-69.

Davis M, Hitchcock JM, Rosen JB (1991) Neural mechanisms of fear conditioning measured with the acoustic startle reflex. In: Neurobiology of learning, emotion and affect (Madden JIV, ed), pp 67-95. New York: Raven.

Eaton RC (1984) Neural mechanisms of starlle behavior. London: Plenum.

Eaton RC, DiDomenico R, Nissanov J (1991) Role of Mauthner cell in sensorimotor integration by brain stem escape network. Brain Behav Evol 37:272-285.

Ebert U, Koch M (1992) Glutamate receptors mediate acoustic input to the reticular brain stem. Neuroreport 3:429-432.

Fleshler M (1965) Adequate acoustic stimulus for startle reaction in the rat. J Comp Physiol Psychol 60:200-207.

Frankland PW, Yeomans JS (1992) Synapses in ventrolateral pons (VLP) and reticularis pontis caudalis (RPC) mediate electrically evoked startle. Soc Neurosci Abstr 18:1547.

Friauf E (1986) Morphology of motoneurons in different subdivisions of rat facial nucleus stained intracellularly with horseradish peroxidase. J Comp Neurol 253:231-241.

Friauf E, Herbert H (1985) Topographic organization of facial motoneurons to individual pinna muscles in rat (Rattus rattus) and bat (Kousettus aegyptiacus). J Comp Neurol 240:161-170.

Friauf E, Ostwald J (1988) Divergent projections of physiologically characterized rat ventral cochlear nucleus neurons as shown by intraaxonal injection of horseradish peroxidase. Exp Brain Res 73:263284.

Goldberg JM, Brown PB (1969) Response of binaural neurons of dog superior olivary complex to dichotic tonal stimuli: some physiological mechanism of sound localization. J Neurophysiol 32:613-636.

Grantyn A, Ong-Meang Jacques V, Berthoz A (1987) Reticulo-spinal neurons participating in the control of synergic eye and head movements during orienting in the cat. II. Morphological properties as revealed by intra-axonal injections of horseradish peroxidase. Exp Brain Res 66:355-377.

Grantyn A, Hardy O, Olivier E, Gourdon A (1992) Relationships between task-related discharge patterns and axonal morphology of brainstem projection neurons involved in orienting eye and head movements. In: Vestibular and brain stem control of eye, head and body movements (Shimazu H, Shinoda Y, eds), pp 255-273. Basel: Karger.

Grillner S, Wallen P, Brodin L, Lansner A (1991) Neuronal network generating locomotor behavior in lamprey: circuitry, transmitters, membrane properties, and simulation. Annu Rev Neurosci 14:169199.

Hammond GR (1973) Lesions of the pontine and medullary reticular formation and prestimulus inhibition of the acoustic startle reaction in rats. Physiol Behav 10:239-243.

Hammond GR, McAdam DW, Ison JR (1972) Effects of prestimulation on the electromyographic response associated with the acoustic startle reaction in rats. Physiol Behav 8:535-537.

Harrison JM, Irving R (1966) The organization of the posterior ventral cochlear nucleus in the rat. J Comp Neurol 126:391-402.

Harrison JM, Warr WB (1962) A study of the cochlear nuclei and ascending auditory pathways of the medulla. J Comp Neurol 119: 341-380.

Harrison JM, Warr WB, Irving R (1962) Second order neurons in the acoustic nerve. Science 138:893-895.

Hitchcock J, Davis M (1986) Lesions of the amygdala, but not of the cerebellum or red nucleus, block conditioned fear as measured with the potentiated startle paradigm. Behav Neurosci 100:11-22.
Hoffman HS, Ison JR (1980) Reflex modification in the domain of startle: I. Some empirical findings and their implications for how the nervous system processes sensory input. Psychol Review 87:175-189.

Hoffman HS, Searle JL (1965) Acoustic variables in the modification of startle reaction in the rat. J Comp Physiol Psychol 60:53-58.

Hoffman HS, Stitt CL, Leitner DS (1980) The optimum interpulse interval for inhibition of acoustic startle in the rat. J Acoust Soc Am 68:1218-1220.

Holstege G, Kuypers HGJM (1982) The anatomy of brain stem pathways to the spinal cord in cat. A labeled amino acid tracing study. Prog Brain Res 57:145-175.

Huffman RF, Henson OW (1990) The descending auditory pathway and acousticomotor systems: connections with the inferior colliculus. Brain Res Rev 15:295-323.

Ison IR, Hammond GR (1971) Modification of the startle reflex in the rat by changes in the auditory and visual environments. J Comp Physiol Psychol 75:435-452.

Ison JR, Hoffman HS (1983) Reflex modification in the domain of startle: II. The anomalous history of a robust and ubiquitous phenomenon. Psychol Bull 94:3-17.

Ison JR, McAdam DW, Hammond GR (1973) Latency and amplitude changes in the acoustic startle reflex of the rat produced by variation in auditory prestimulation. Physiol Behav 10:1035-1039.

Jones BE, Yang TZ (1985) The efferent projections from the reticular formation and the locus coeruleus studied by anterograde and retrograde axonal transport in the rat. J Comp Neurol 242:56-92.

Kandel ER (1991) Cellular mechanisms of learning and the biological basis of individuality. In: Principles of neural science (Kandel ER, Schwartz JH, Jessell TM, eds), pp 1009-1032. Amsterdam: Elsevier.

Kandler K, Herbert H (1991) Auditory projections from the cochlear nucleus to pontine and mesencephalic reticular nuclei in the rat. Brain Res 562:230-242.

Klepper A, Herbert H (1992) Anatomical connections of the ventrolateral tegmental nucleus in the rat. Eur J Neurosci [Suppl] 5:2275.

Koch M, Ebert U (1993) Enhancement of the acoustic startle response by stimulation of an excitatory pathway from the central amygdala/ basal nucleus of Meynert to the pontine reticular formation. Exp Brain Res 93:231-241.

Koch M, Lingenhöhl K, Pilz PKD (1992) Loss of the acoustic startle response following neurotoxic lesions of the caudal pontine reticular formation: possible role of giant neurons. Neuroscience 49:617-625.

Kolston J, Osen KK, Hackney CM, Ottersen OP, Storm-Mathisen J (1992) An atlas of glycine-like and GABA-like immunoreactivity and colocalization in the cochlear nuclear complex of the guinea pig. Anat Embryol (Berl) 186:443-465.

Landis C, Hunt W (1939) The startle pattern. New York: Farrar and Rinehart.

Leaton RN (1976) Long-term retention of the habituation of lick suppression and startle response produced by a single auditory stimulus. J Exp Psychol [Anim Behav] 2:248-259.

Leitner DS, Powers AS, Hoffman HS (1980) The neuronal substrate of the startle response. Physiol Behav 25:291-297.

Lingenhöhl K, Friauf E (1992) Giant neurons in the caudal pontine reticular formation receive short latency acoustic input: an intracellular recording and HRP-study in the rat. J Comp Neurol 325:473492.

Lingenhöhl K, Friauf E, Koch M (1991) Giant neurons in the caudal pontine reticular formation relay the acoustic startle response in the rat. Soc Neurosci Abstr 17:468.

López DE, Merchán MA, Bajo VM, Saldaña E (1993) The cochlear root neurons in the rat, mouse and gerbil. In: The mammalian cochlear nucleus: organization and function (Merchán M, Juiz JM, Godfrey DA, Mugnaini E, eds), pp 171-180. New York: Plenum.

Marsh R, Hoffman HS, Stitt CL (1973) Temporal integration in the acoustic startle reflex of the rat. J Comp Physiol Psychol 82:507-511.

Merchán MA, Collia F, López DE, Saldaña E (1988) Morphology of cochlear root neurons in the rat. J Neurocytol 17:711-725.

Miserendino MJD, Davis M (1993) NMDA and non-NMDA antagonists infused into the nucleus reticularis pontis caudalis depress the acoustic startle reflex. Brain Res 623:215-222.

Mitani A, Ito K, Mitani Y, McCarley RW (1988a) Morphological and electrophysiological identification of gigantocellular tegmental field neurons with descending projections in the cat: I. Pons. J Comp Neurol 268:527-545.

Mitani A, Ito K, Mitani Y, McCarley RW (1988b) Descending projections from the gigantocellular tegmental field in the cat: cells of 
origin and their brainstem and spinal cord trajectories. J Comp Neurol 268:546-566.

Moyer KE (1963) Startle response: habituation over trials and days, and sex and strain differences. J Comp Physiol Psychol 56:863-865.

Müller $G$, Klingberg F (1989) Lesions of the caudal pontine reticular nucleus reduce spontaneous behavioural activity of rats differently in dorsal and ventral parts of the nucleus. Biomed Biochim Acta 48: $807-816$.

Newman DB (1985) Distinguishing rat brainstem reticulospinal nuclei by their neuronal morphology. II. Pontine and mesencephalic nuclei. J Hirnforsch 26:385-418.

Pellet J (1990) Neuronal organization in the brainstem circuit mediating the primary acoustic head startle: an electrophysiological study in the rat. Physiol Behav 48:727-739.

Peterson BW, Franck JI, Pitts NG, Daunton NG (1976) Changes in responses of medial pontomedullary reticular neurons during repetitive cutaneous, vestibular, cortical and tectal stimulation. J Neurophysiol 39:564-581.

Pilz PKD (1989) Die akustisch ausgelöste Schreckreaktion bei der Ratte. PhD thesis, Universität Tübingen.

Pilz PKD, Schnitzler H-U, Menne D (1987) Acoustic startle threshold of the albino rat (Rattus norvegicus). J Comp Psychol 101:67-72.

Pilz PKD, Caeser M, Ostwald J (1988) Comparative threshold studies of the acoustic pinna, jaw and startle reflex in the rat. Physiol Behav $43: 411-415$.

Preuß S (1991) Elektrophysiologische und neuroanatomische Charakterisierung der Kerne des lateralen Lemniscus und der umgebenden auditorischen Areale bei der Ratte. PhD thesis, Universität Tübingen.

Prosser CL, Hunter WS (1936) The extinction of startle responses and spinal reflexes in the white rat. Am J Physiol 117:609-618.

Roberts A (1990) How does a nervous system produce behaviour? A case study in neurobiology. Sci Prog 74:31-51.

Rosen JB, Davis M (1988) Temporal characteristics of enhancement of startle by stimulation of the amygdala. Physiol Behav 44:117-123.

Rosen JB, Davis M (1990) Enhancement of electrically elicited startle by amygdaloid stimulation. Physiol Behav 48:343-349.

Rosen JB, Hitchcock JM, Sananes CB, Miserendino MJD, Davis M (1991) A direct projection from the central nucleus of the amygdala to the acoustic startle pathway: anterograde and retrograde tracing studies. Behav Neurosci 105:817-825.
Ross MD, Burkel W (1971) Electron microscopic observations of the nucleus, glial dome, and meninges of the rat acoustic nerve. Am J Anat 130:73-92.

Shammah-Lagnado SJ, Negrao N, Silva BA, Ricardo JA (1987) Afferent connections of the nuclei reticularis pontis oralis and caudalis: a horseradish peroxidase study in the rat. Neuroscience 20:961-989.

Siegel JM (1979) Behavioral functions of the reticular formation. Rrain Res Rev 1:69-105.

Siegel JM, McGinty DJ (1977) Pontine reticular formation neurons: relationship of discharge to motor activity. Science 196:678-680.

Siegel JM, Tomaszewski KS (1983) Behavioral organization of reticular formation: studies in the unrestrained cat. I. Cells related to axial, limb, cyc and other movements. J Neurophysiol 50:696-716.

Sommer I, Lingenhöhl K, Friauf E (1993) Principal cells of the rat medial nucleus of the trapezoid body: an intracellular in vivo study of their physiology and morphology. Exp Brain Res 95:223-239.

Sternberger LA (1979) Immunohistochemistry. New York: Wiley.

Szabó I, Hazafi K (1965) Elicitability of the acoustic startle reaction after brain stem lesions. Acta Physiol Acad Sci Hung 27:155-165.

Taber E (1961) The cytoarchitecture of the brainstem of the cat. J Comp Neurol 116:27-69.

Tohyama M, Sakai K, Salvert D, Touret M, Jouvet M (1979) Spinal projections from the lower brain stem in the cat as demonstrated by the horseradish peroxidase technique. I. Origins of the reticulospinal tracts and their funicular trajectories. Brain Res 173:283-403.

Valverde F (1961) Reticular formation of the pons and medulla oblongata. A Golgi study. J Comp Neurol 116:71-99.

Wu M-F, Suzuki SS, Siegel JM (1988) Anatomical distribution and response patterns of reticular neurons active in relation to acoustic startle. Brain Res 457:399-406.

Yajima Y, Hayashi Y (1989) Response properties and tonotopical organization in the dorsal cochlear nucleus in rats. Exp Brain Res 75: 381-389.

Yao W, Godfrey DA (1992) Quantitative evidence that cochlear root neurons are not cholinergic. Soc Neurosci Abstr 18:1036.

Yeomans JS, Rosen JB, Barbeau J, Davis M (1989) Double-pulse stimulation of startle-like responses in rats: refractory periods and temporal summation. Brain Res 486:147-158. 